\title{
The Elachistinae (Lepidoptera: Gelechioidea, Elachistidae) of Thailand, with description of eight new species
}

\author{
Virginijus SRUOGA ${ }^{1}$, Lauri KAILA ${ }^{2} \&$ Agnè ROCIENE ${ }^{3}$ \\ ${ }^{1,3}$ Vytautas Magnus University, Education Academy, K. Donelaičio 58, LT-44248 Kaunas, Lithuania. \\ ${ }^{2}$ Finnish Museum of Natural History, Zoology Unit, University of Helsinki, \\ P.O. Box 17, FI-00014 Helsinki, Finland. \\ ${ }^{1}$ Corresponding author: virginijus.sruoga@vdu.lt \\ 2Email: lauri.kaila@helsinki.fi \\ ${ }^{3}$ Email: agne.rociene@vdu.lt \\ ${ }^{1}$ urn:1sid:zoobank.org:author:9AEF8A6F-7EA1-480A-9054-6319EE00892E \\ ${ }^{2}$ urn:lsid:zoobank.org:author:36281398-B1A4-4B14-9D19-DA43403F9A14 \\ ${ }^{3}$ urn:1sid:zoobank.org:author:0DFE9CBF-D8A4-4C0E-8D44-5A750C76674D
}

\begin{abstract}
First records of Elachistinae are given from Thailand. Ten species of Elachistinae are reported, eight of which are described as new: Urodeta longa Sruoga \& Kaila sp. nov., Elachista buszkoi Sruoga \& Kaila sp. nov., E. oryx Sruoga \& Kaila sp. nov., E. pellineni Sruoga \& Kaila sp. nov., E. capricornis Sruoga \& Kaila sp. nov., E. phichaiensis Sruoga \& Kaila sp. nov., E. loeiensis Sruoga \& Kaila sp. nov. and $E$. siamensis Sruoga \& Kaila sp. nov. The new species are diagnosed and illustrated with photographs of the adults and genitalia. One species remains unidentified to species level.
\end{abstract}

Keywords. Elachistidae, Elachista, Urodeta, new species, Thailand.

Sruoga V., Kaila L. \& Rocienè A. 2019. The Elachistinae (Lepidoptera: Gelechioidea, Elachistidae) of Thailand, with description of eight new species. European Journal of Taxonomy 574: 1-34.

https://doi.org/10.5852/ejt.2019.574

\section{Introduction}

The subfamily Elachistinae Bruand, 1850 (family Elachistidae Bruand, 1850) belongs to the megadiverse lepidopteran superfamily Gelechioidea Stainton, 1854 and contains presently 805 described species considered valid (Kaila 2019). The moths are small, with wingspan of 4-20 mm (Kaila 2011). The head is smooth-scaled with a weakly raised neck tuft, and a short, basally scaled haustellum. The antenna extends to about $2 / 3$ of the forewing. The forewing pattern often consists either of a white fascia and spots on a dark background, or fuscous marks on a light background; or the moths can be more or less unicolorous (white, yellowish white, or creamy). The moths rest in a characteristic posture: the antennae are directed backwards along the costal margin of the forewing and the tornal area of the forewing is produced above the dorsum. The male genitalia are symmetrical, usually with a spinose distal knob of gnathos and bilobed uncus. Larvae are obligate leaf miners, species of the largest genus of the subfamily, Elachista Treitschke, 1833 feed on monocots (almost solely grasses or sedges); species belonging to the smaller genera Perittia 
Stainton, 1854, Stephensia Stainton, 1858 and Urodeta Stainton, 1869 with known life history feed on dicotyledonous plants (Traugott-Olsen \& Nielsen 1977; Parenti \& Varalda 1994).

Although the Elachistinae are cosmopolitan in distribution, only the Holarctic and Australian faunas can be considered to have been relatively well investigated (Braun 1948; Traugott-Olsen \& Nielsen 1977; Bland 1996; Sinev \& Sruoga 1997; Sugisima 2005a, 2005b; Sugisima \& Kaila 2005; Kaila 1995, 1996, 1997, 1999b, 2011, 2015a, 2015b, 2017; Kaila et al. 2015; Sruoga et al. 2017; Kaila \& Nupponen 2017,2018 , etc.). However, many regions are still very poorly known in terms of elachistine species composition. One such place is the Thailand, from where no data on Elachistinae were hitherto published.

Investigation of the material from the Finnish Museum of Natural History of the University of Helsinki, Finland and from the Zoological Museum of University of Copenhagen, Denmark has resulted in the discovery of ten species, eight of which are described as new. Following the classification of Kaila \& Sugisima (2011), the species are grouped as follows: one species is attributed to the genus Urodeta, the rest to Elachista: one to the E. orba species group, four to the E. saccharella species group sensu lato, one to the E. praelineata species group and three to the E. freyerella species group.

\title{
Material and methods
}

Adult specimens were examined externally using a MBS-10 and Euromex Stereo Blue stereo microscopes. The forewing length was measured along the costa from wing base to the apex of the terminal fringe scales. For a wingspan, the forewing length was doubled and thorax width added. The width of the head was measured between the inner edges of the antennal bases. Genitalia were prepared following the standard method described by Robinson (1976) and Traugott-Olsen \& Nielsen (1977). The genitalia were studied and some morphological structures were photographed in glycerol before permanent slide-mounting in Euparal. The male genital capsule was stained with fuchsin and the abdominal pelt and female genitalia with chlorazol black (Direct Black 38/Azo Black). The genital morphology was examined using Novex B and Leica DM 2500 microscopes. The photographs of adults were taken using a Leica S6D stereo microscope and Leica DFC290 digital camera. The photographs of genitalia were made using a Leica DM2500 microscope and a Leica DFC420 digital camera. The descriptive terminology of morphological structures follows Traugott-Olsen \& Nielsen (1977), Kaila (1999a, 2011), and Kristensen (2003). The specific epithets of the new species are nouns in apposition.

\section{Repositories}

$\mathrm{MZH}=$ Finnish Museum of Natural History, University of Helsinki, Finland

$\mathrm{VMU}=$ Education Academy, Vytautas Magnus University, Vilnius, Lithuania

ZMUC = Zoological Museum - University of Copenhagen, Denmark

\section{Results}

\author{
Class Insecta Linnaeus, 1758 \\ Order Lepidoptera Linnaeus, 1758 \\ Superfamily Gelechioidea Stainton, 1854 \\ Family Elachistidae Bruand, 1850 \\ Subfamily Elachistinae Bruand, 1850 \\ Genus Urodeta Stainton, 1869 \\ Urodeta longa Sruoga \& Kaila sp. nov. \\ urn:Isid:zoobank.org:act:D165B203-109C-4166-BA2D-68228B2FF097
}

Figs 1-6

\section{Diagnosis}

Urodeta longa Sruoga \& Kaila sp. nov. is a small, lightly-coloured species, with indistinct wing markings. It lacks the distinctive black markings that characterize the single other known Oriental 
Urodeta species, U. noreikai Sruoga \& De Prins, which is known from Nepalese Himalayas (Sruoga \& De Prins 2013). The female genitalia are highly distinctive with a very large antrum having large internal spines. As such, $U$. longa Sruoga \& Kaila sp. nov. cannot be confused with any other known species of Urodeta.

\section{Etymology}

The species name is derived from the Latin 'longa' (long) in reference to the unusually long papillae anales.

\section{Type material}

\section{Holotype}

THAILAND • ; ; Lampang, Muban Phichai; 4 Mar. 2017; M.J. Pellinen leg.; MZH VS1/29.03.19.

\section{Description}

\section{Female}

EXTERNAL CHARACTERS (Figs 1-2). Forewing length $2.3 \mathrm{~mm}$; wingspan $4.9 \mathrm{~mm}(\mathrm{n}=1)$. Head: frons, vertex and neck tuft white, mottled with light brown tipped scales; labial palpus straight, very short, white; scape white, mottled with light brown, pecten white; flagellum greyish brown annulated with paler rings, serrate distally. Thorax, tegula and forewing strongly mottled with scales basally white and distally creamy brown; light brown-tipped scales forming two small blurred spots, one at $2 / 5$ and another at $2 / 3$ of wing; fringe scales creamy white with some blackish brown tipped scales. Hindwing brownish grey, its fringe scales somewhat paler.

Female genitalia (Figs 3-6). Papilla analis sclerotized, longer than wide, sparsely covered with long setae. Apophysis posterioris very short. Apophysis anterioris weakly sclerotized except at apices, extending from central part of segment and spreading apart laterad. Ostium bursae situated in membrane between sterna 7 and 8 . Sternum 8 membranous, with sclerotized, posteriorly curved band. Antrum large, oval, strongly sclerotized, with about 24 large and several small internal spines. Colliculum shorter than antrum, membranous, with minute internal spines. Ductus bursae about 3.8 times as long as antrum, membranous, without internal spines. Corpus bursae without signum or internal spines.

\section{Male \\ Unknown.}

\section{Biology}

Unknown.

\section{Flight period}

The only known specimen was captured in March by artificial light.

\section{Distribution}

So far this species is known only from northern Thailand. We have decided to describe and name it in spite of the paucity of the material. We made this decision as this record considerably extends the known distribution of the genus, filling a large gap between Nepal and Australia that are the closest known occurrences for this genus. 


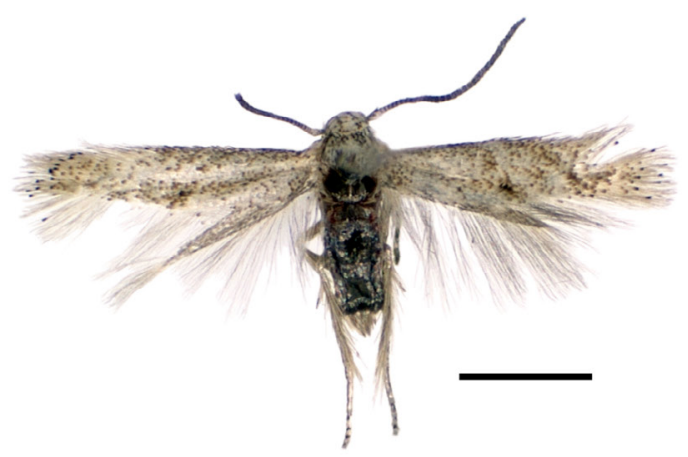

1
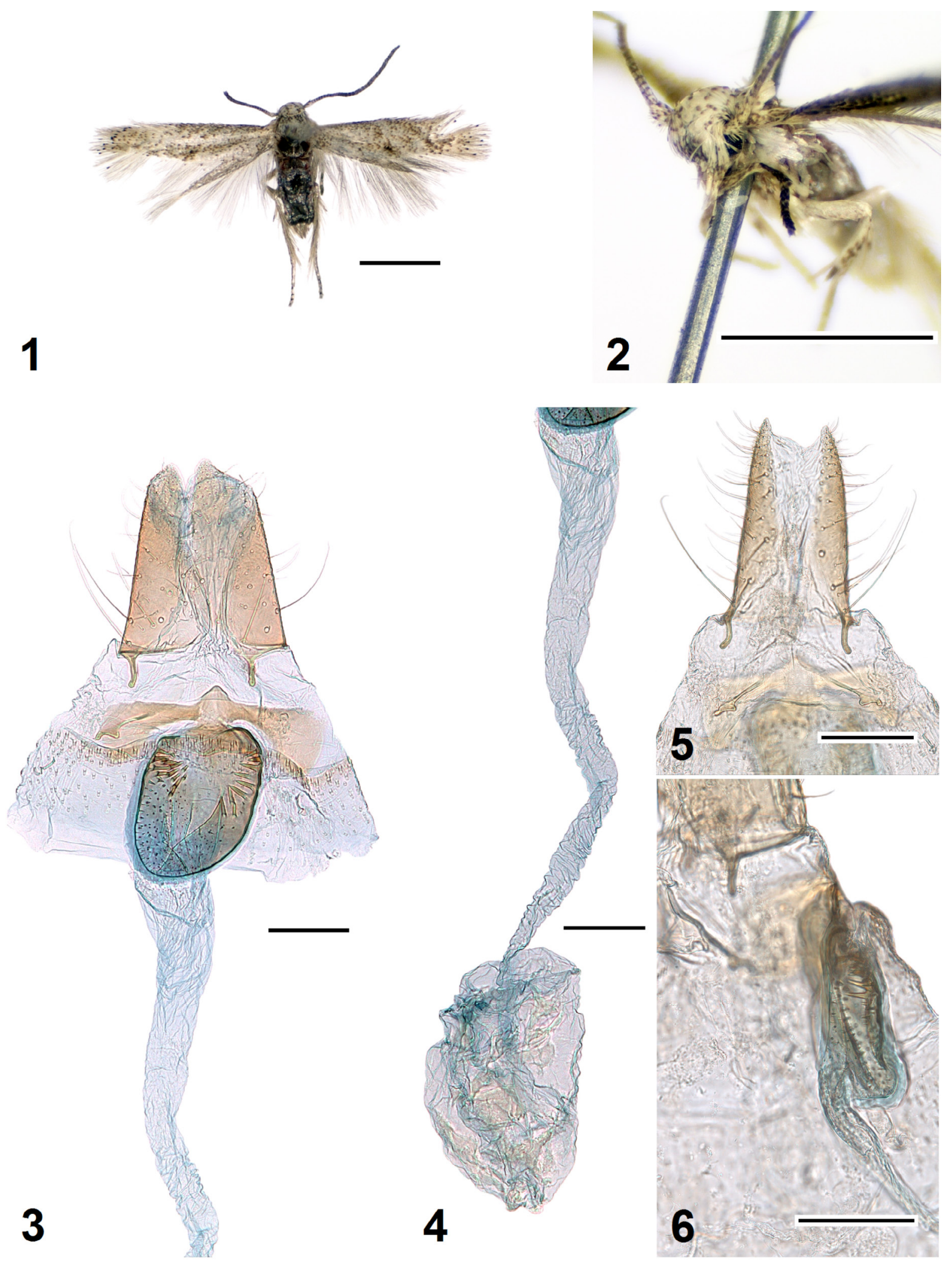

Figs 1-6. Urodeta longa Sruoga \& Kaila sp. nov., holotype, ㅇ (MZH VS1/29.03.19, in glycerol before permanent mounting in Euparal). 1. Adult. 2. Head, latero-frontal view. 3. Caudal part of female genitalia. 4. Ductus and corpus bursae. 5. Papillae anales and apophyses, dorsal view. 6. Antrum, lateral view. Scale bars: $1-2=1 \mathrm{~mm} ; 3-6=0.1 \mathrm{~mm}$. 
Genus Elachista Treitschke, 1833

Elachista buszkoi Sruoga \& Kaila sp. nov. urn:Isid:zoobank.org:act:4BD9729D-5F30-468A-ACD3-26722E91E521

Figs $7-13$

\section{Diagnosis}

Elachista buszkoi Sruoga \& Kaila sp. nov. belongs to the E. orba species group (defined by Kaila 2011). It is a small, dark-coloured species with indistinct wing markings. In wing pattern and male genitalia, the new species is comparable to E. commoncommelinae Sugisima \& Kaila, 2011 and E. nielsencommelinae Sugisima \& Kaila, 2011 known from Australia (for illustrations, we refer to Kaila 2011: pl. 13, figs 14-15; pl. 14, figs 1-2; figs 274-278). However, E. buszkoi Sruoga \& Kaila sp. nov. is distinguishable by silvery grey fasciae on forewing, much smaller and wider separate uncus lobes, and more bent phallus.

\section{Etymology}

This new species is dedicated to Professor Jaroslaw Buszko, who collected the type material.

\section{Type material}

Holotype

THAILAND • \; Doi Ithanon; 1200 m; larva 9 Nov. 2010, ex larva 25 Nov. 2010; J. Buszko leg.; MZH VS1/2.04.19.

\section{Paratype}

THAILAND • 1 त; same collection data as for the holotype; MZH VS2/29.03.19.

\section{Description}

\section{Male}

EXTERNAL CHARACTERS (Figs 7-8). Forewing length 2.6-2.7 mm; wingspan 5.8-6.0 mm $(\mathrm{n}=2)$. Head: frons shiny, brownish white; vertex and neck tuft brownish black; labial palpus upwards curved, slightly longer than width of head, blackish brown except second segment white above; antenna blackish brown, very weakly annulated with paler rings, somewhat serrate, without pecten; densely ciliated, length of cilia about $1 / 2$ diameter of shaft. Thorax, tegula and ground colour of forewing brownish black, with two silvery grey, weakly outwardly bent, transverse fasciae at $1 / 4$ and $1 / 2$ of wing; fringe scales greyish brown, fringe line brownish black. Hindwing greyish brown, its fringe scales somewhat paler.

Male genitalia (Figs 9-13). Uncus lobes short, narrow, with broad U-shaped gap between them, bottom of gap reinforced, ventral surface with few short, thin scales. Basal arms of gnathos short, strongly sclerotized; spinose knob of gnathos divided into two large oval lobes. Valva 3.5 times as long as wide, evenly bent, broadest medially, basal fold of costa extended to $1 / 2$ length of valva, beyond it broad hump; cucullus rounded; sacculus with very small distal spine. Digitate process about $1 / 5$ length of valva, broadest at base, apex with few small setae. Median plate of juxta with prominent dorsally directed pockets in lateral margin (Fig. 13); juxta lobes small, median margin straight, apical margin somewhat convex, with few small setae laterally. Vinculum V-shaped, without median ridge, tapered to short saccus. Phallus 0.8 length of valva, strongly bent at basal $2 / 5$; basal opening posteriorly directed, without caecum; no cornuti present.

\section{Female}

Unknown. 


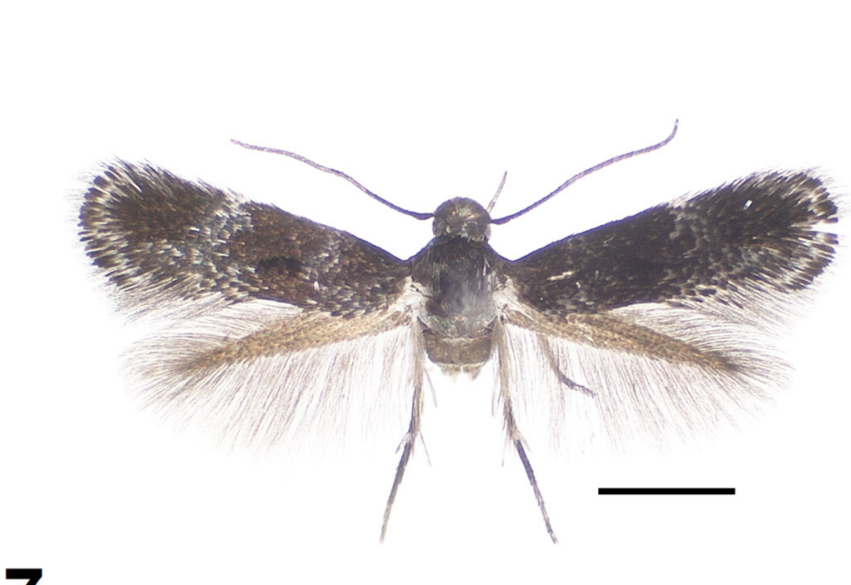

7
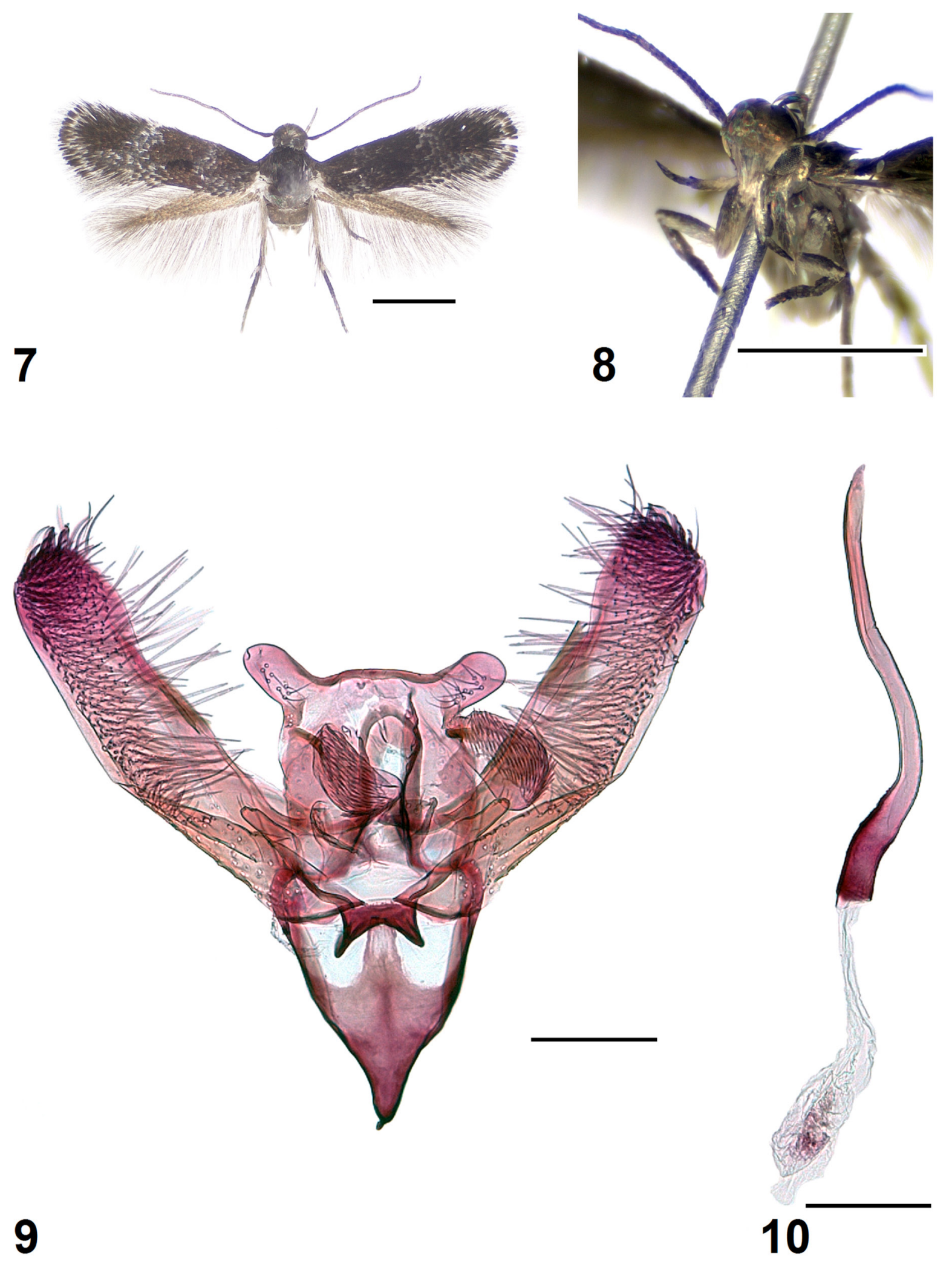

Figs 7-10. Elachista buszkoi Sruoga \& Kaila sp. nov., holotype, ô (MZH VS1/2.04.19). 7. Adult. 8. Head, latero-frontal view. 9. General view of male genitalia (phallus removed). 10. Phallus. Scale bars: $7-8=1 \mathrm{~mm} ; 9-10=0.1 \mathrm{~mm}$. 


\section{Biology}

The mined leaves of an unidentified Poaceae sp. were collected in early November. All other known species of the E. orba species group feed on plants belonging to Zingiberales Grisebach or Commelinales Mirb. ex Bercht. \& J.Presl. This is the first record of a Poaceae Barnhart feeding species in this group.

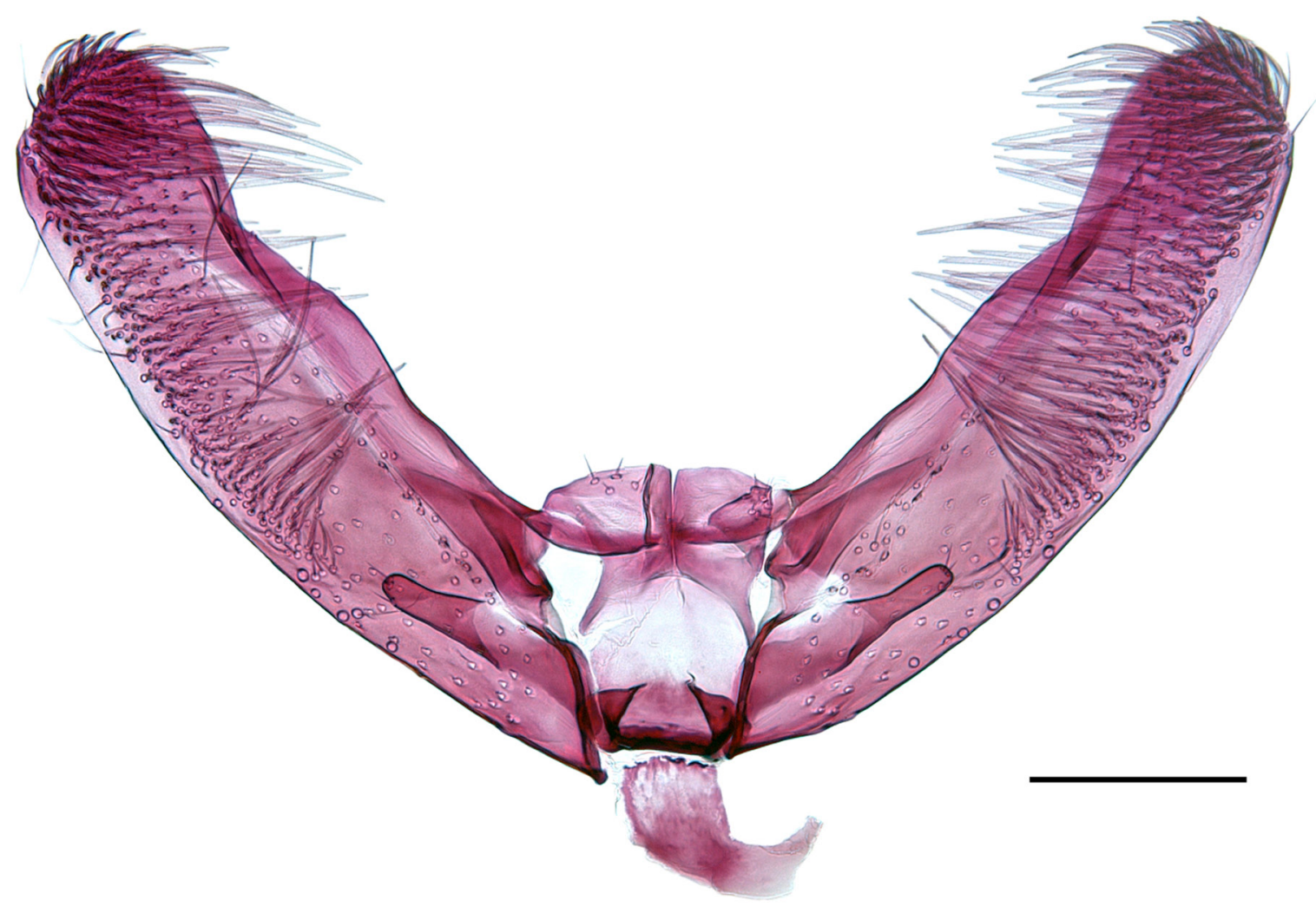

11
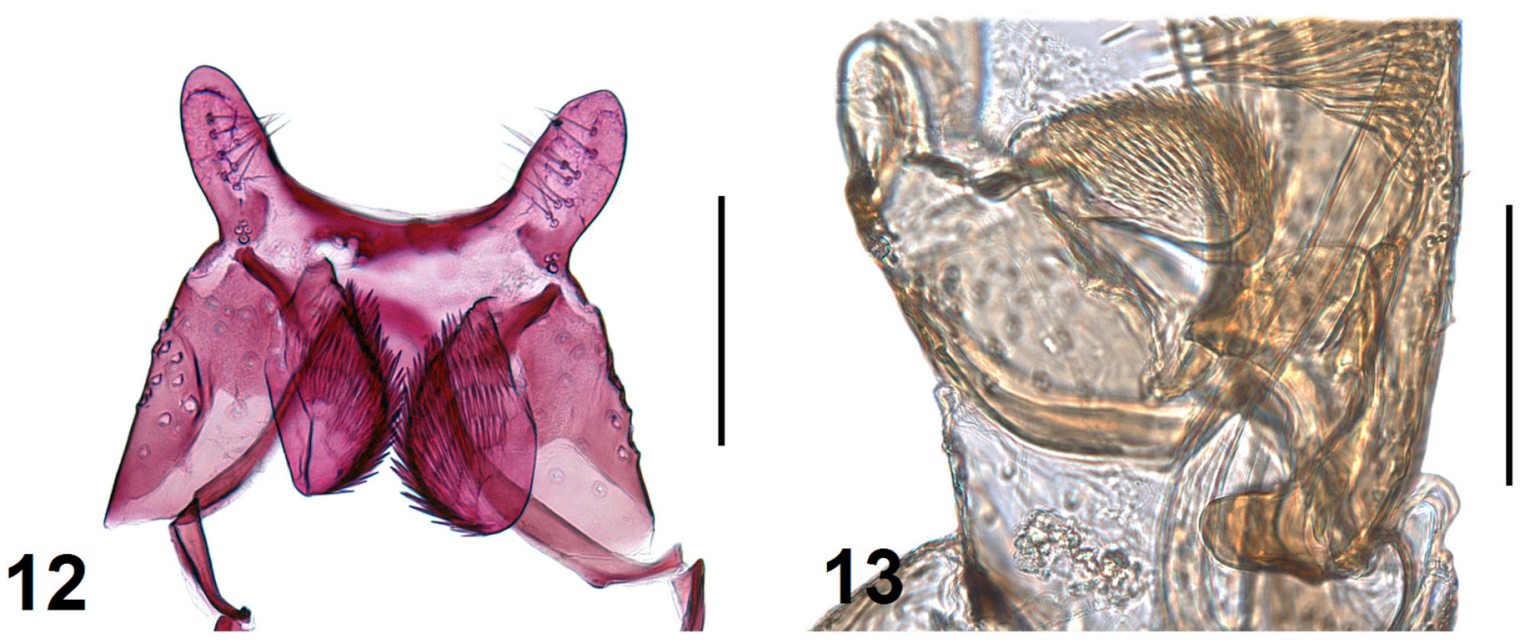

Figs 11-13. Elachista buszkoi Sruoga \& Kaila sp. nov., paratype, đ̊ (MZH VS2/29.03.19). 11. Valvae, juxta and digitate processes. 12. Tegumen, uncus and gnathos. 13. Juxta, tegumen and gnathos, lateral view (in glycerol before permanent mounting in Euparal). Scale bars $=0.1 \mathrm{~mm}$. 


\section{Flight period}

Based upon the two specimens available, adults fly in late November.

\section{Distribution}

So far this species is known only from northern Thailand.

Elachista amamii Parenti, 1983

\section{Material examined}

THAILAND • 1 ภ, 1 क; Loei Province, Phu Luang Wildlife Sanctuary; 700-900 m; 8-14 Oct. 1984;

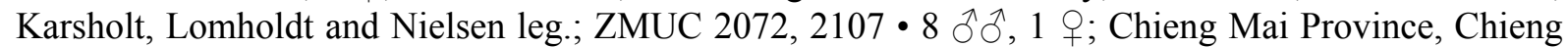
Mai; 325 m; 15-30 Oct. 1984; Karsholt, Lomholdt and Nielsen leg.; ZMUC 1501, 1502, 2108 to 2112, 2502 • ${ }^{\top}$; Lampang, Muban Phichai; 18¹8'15" N, 99³1'06" E; 23 Sep. 2014; M.J. Pellinen leg.; MZH VS1/21.11.18.

\section{Distribution}

Japan (Parenti 1983), Taiwan (Sugisima 2005a).

\section{Remarks}

Elachista amamii is illustrated by Parenti (1983) and Sugisima (2005a). It belongs to the Elachista praelineata species group as defined by Kaila (1999b). It is similar to E. brachyplectra Meyrick, 1921, which has a more southern distribution (Sri Lanka, Indonesia). Elachista amamii can be separated from it by the absence of the digitate process in E. brachyplectra (Sruoga 2005).

Elachista oryx Sruoga \& Kaila sp. nov. urn:1sid:zoobank.org:act:71CD1D33-4385-478F-B455-AAB1353ADD58

Figs 14-23

\section{Diagnosis}

Elachista oryx Sruoga \& Kaila sp. nov. is a small species with peculiarly coloured forewings (Fig. 14) and a dorsoventrally flattened head, atypical of Elachista in general but typical of related species in the E. albrechti-heteroplaca species group (cf. Kaila 1998). In wing pattern and male genitalia, this species is most similar to Elachista heteroplaca Meyrick, 1934 (for illustrations, we refer to Kaila 1998: figs 1-5). The main differences in male genitalia between E. oryx Sruoga \& Kaila sp. nov. and E. heteroplaca are: 1) digitate process in E. oryx Sruoga \& Kaila sp. nov. is short and wide (Figs 16, 18), devoid of setae, in E. heteroplaca it is long and slender, with setae; 2) juxta lobe in E. oryx Sruoga \& Kaila sp. nov. very long and narrow, in E. heteroplaca it is much shorter and wide; 3) vinculum in E. oryx Sruoga \& Kaila sp. nov. is short, width/length ratio about 0.7 whereas in E. heteroplaca it is longer, width/length ratio about $0.4 ; 4)$ phallus in E. oryx Sruoga \& Kaila sp. nov. is wide, long/ width ratio about 19, in E. heteroplaca it is slender, long/width ratio about 30; 5) in E. oryx Sruoga \& Kaila sp. nov. the stout spine of valva is comparatively short, about 7.5 times as long as wide, in E. heteroplaca it is longer, about 12 times as long as wide; 6) vesica is with numerous tiny spines in E. oryx Sruoga \& Kaila sp. nov., whereas in E. heteroplaca vesica is without such spines; 7) the boomerang-shaped sclerotization of tergum 8 in E. oryx Sruoga \& Kaila sp. nov. (Fig. 23) is noticeably wider than in E. heteroplaca. 

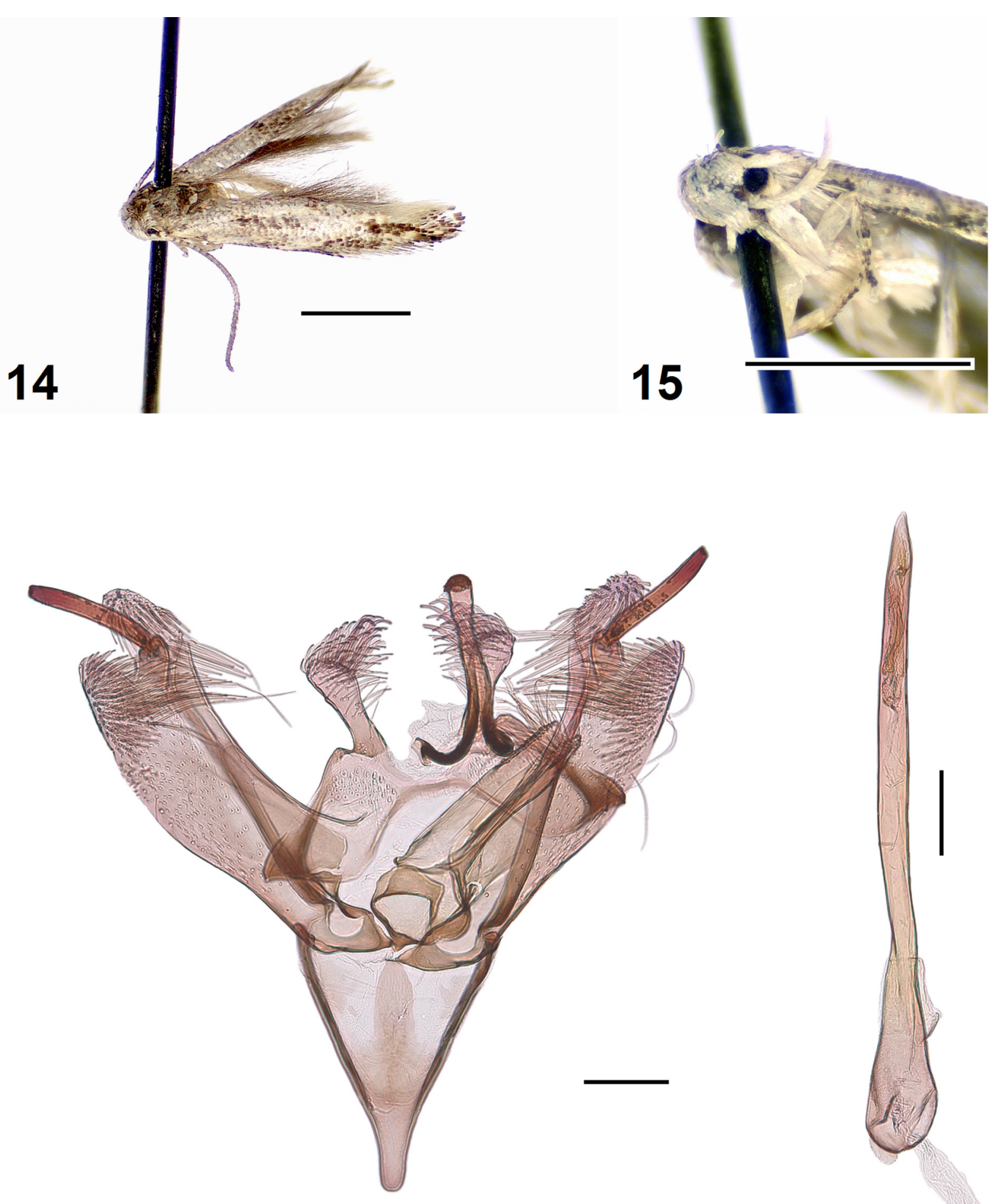

\section{6}

Figs 14-17. Elachista oryx Sruoga \& Kaila sp. nov., holotype, đ̊ (MZH VS1/23.11.18). 14. Adult. 15. Head, latero-frontal view. 16. General view of male genitalia (phallus removed). 17. Phallus. Scale bars: $14-15=1 \mathrm{~mm} ; 16-17=0.1 \mathrm{~mm}$. 


\section{Etymology}

The species name is derived from the Latin 'oryx' (a kind of antelope or gazelle) in reference to the long, horn-like spines of valvae.

\section{Type material}

\section{Holotype}

THAILAND • đ’; Lampang, Muban Phichai; 18¹8'15" N, 99³1'06" E; 12 Jan. 2012; M.J. Pellinen leg.; MZH VS1/23.11.18.

\section{Description}

\section{Male}

EXTERNAL CHARACTERS (Figs 14-15). Forewing length $2.6 \mathrm{~mm}$; wingspan $5.8 \mathrm{~mm}(\mathrm{n}=1)$. Head: frons shiny whitish; vertex and neck tuft brownish grey, some scales with dark brown tips; labial palpus upwards curved, about 1.7 times as long as width of head, creamy white, third segment medially with few dark brown scales on outer side; scape creamy white, without pecten; flagellum greyish brown, basal articles weakly annulated with paler rings. Thorax dark grey brown. Forewing: ground colour light greyish brown, costa narrowly dark except at $1 / 5$ where indistinctly delimited oblique white streak and at $2 / 5$ where larger oblique white streak almost reaches fold; in the middle of wing at fold dark brown spot formed of slightly raised scales; tornal area whitish; narrow longitudinal blackish brown stripe to apex of wing; fringe scales greyish, fringe line blackish brown. Hindwing and its fringe scales greyish brown.

Male Genitalia (Figs 16-23). Uncus lobes widely apart from each other, narrow, elongate, basally weakly dilated, distally distinctly broadened, ventral surface densely covered with long, hair-like scales. Tegumen short, anterior margin dorsomedially strongly and widely indented, almost meeting posterior margin. Basal arms of gnathos very long, basally strongly melanized, and strongly bent towards posterior direction, apically fused and covered with several tiny spines; spinose knob small, spinose area directed apically. Costa of valva weakly concave; from distal fold of costa long, strongly sclerotized spine, length of which almost $1 / 3$ of that of valva. Cucullus divided into two lobes: wide triangular lobe where sacculus meets cucullus, and another slightly longer, narrow lobe in costal side. Digitate process short and wide, triangular, devoid of setae. Median plate of juxta with two pockets: anteriorly directed small, triangular pocket at ventral side, and posteriorly directed large and wide one at dorsal side. Juxta lobes long and narrow, tapering to apex, median margin straight and distinctly sclerotized, distal margin with few tiny setae and dorsally directed large group of long hair-like scales. Vinculum long, v-shaped, saccus short, blunt-tipped. Phallus about 1.4 length of valva, basally dilated, straight except apex slightly bent; caecum short, rounded with sclerotized ridge forming two small lobes; vesica with group of minute spines, distally joined with two sclerotized longitudinal plates; one long bent cornutus.

\section{Female}

Unknown.

\section{Biology}

Unknown. The specimen was collected by artificial light.

\section{Flight period}

The only known specimen was captured in mid-January.

\section{Distribution}

So far this species is known only from northern Thailand. 


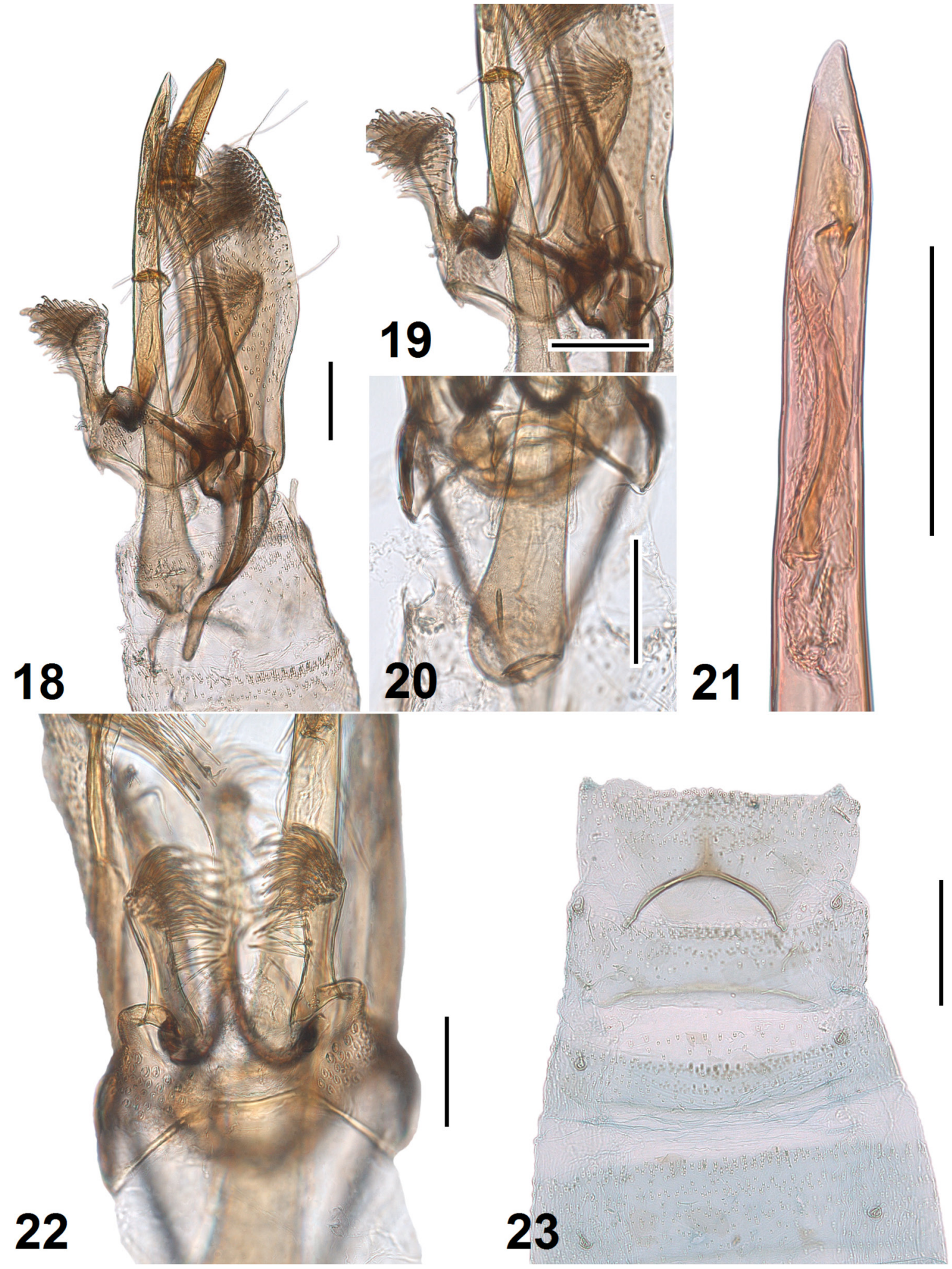

Figs 18-23. Elachista oryx Sruoga \& Kaila sp. nov., genitalia, holotype, $\widehat{\sigma}$ (MZH VS1/23.11.18, in glycerol before permanent mounting in Euparal). 18. Lateral view. 19. Juxta, lateral view. 20. Proximal part of phallus. 21. Distal part of phallus. 22. Uncus lobes, dorsal view. 23. Distal part of abdomen, dorsal view. Scale bars $=0.1 \mathrm{~mm}$. 


\section{Elachista pellineni Sruoga \& Kaila sp. nov. urn:lsid:zoobank.org:act:2D8B8809-389A-486E-B79A-6EA153F34425}

Figs $24-39$

\section{Diagnosis}

Elachista pellineni Sruoga \& Kaila sp. nov. is a small species with peculiarly coloured forewings (Figs 24, 35) and dorsoventrally flattened head. In wing pattern and male genitalia, the new species is comparable to E. heteroplaca (for illustrations, we refer to Kaila 1998: figs 1-5) and E. oryx Sruoga \& Kaila sp. nov., known from the same locality. However, E. pellineni Sruoga \& Kaila sp. nov. is distinguishable by the much longer digitate processes, the juxta lobe strongly produced posteriorly and the wider uncus lobes. The female genitalia are very distinctive with the invagination of integument between sterna 7 and 8 densely filled with dark scales.

\section{Etymology}

The species named after Markku J. Pellinen, who collected the type material.

\section{Type material}

\section{Holotype}

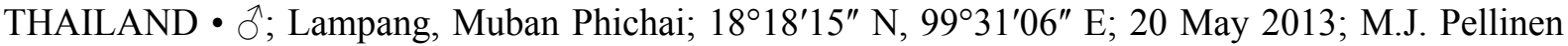
leg.; MZH VS2/23.11.18.

\section{Paratypes}

THAILAND • 1 ऊ; same locality as for holotype; 27 Sep. 2016; M.J. Pellinen leg; MZH VS1/22.11.18 • 1 ; Phichai; 18²0'42" N, 99³2'52" E; 28 May 2004; M.J. Pellinen leg.; MZH VS1/24.11.18.

\section{Description}

\section{Male}

EXTERNAL CHARACTERS (Figs 24-25). Forewing length 2.6-2.8 mm; wingspan 5.8-6.2 mm ( $\mathrm{n}=2)$. Head: frons shiny, creamy white; vertex and neck tuft brownish white, some scales with dark brown tips; labial palpus upwards curved, about 1.7 times as long as width of head, creamy white, third segment medially with few dark brown scales on outer side; scape creamy white below, with few dark brown scales above, without pecten; flagellum creamy white below, greyish brown above, annulated with paler rings, last flagellomere creamy white. Thorax grey brown. Forewing: ground colour greyish brown, costa narrowly dark except at $1 / 5$ where indistinctly delimited oblique white streak and at $2 / 5$ where larger oblique white streak almost reaches fold; in the middle of wing at fold dark brown spot formed of raised scales; tornal area whitish; narrow longitudinal blackish brown stripe to apex of wing; fringe scales brownish grey, fringe line blackish brown. Hindwing and its fringe scales brownish grey.

Male Genitalia (Figs 26-34). Uncus lobes widely apart from each other, elongate, basally dilated, distally distinctly broadened, ventral surface densely covered with long, hair-like scales. Tegumen short, anterior margin dorsomedially strongly and widely indented, almost meeting posterior margin. Basal arms of gnathos very long, basally strongly melanized, and strongly bent towards posterior direction, apically fused and covered with several tiny spines; spinose knob small, spinose area directed apically. Costa of valva weakly concave; from distal fold of costa long, strongly sclerotized spine, length of which about $2 / 5$ of that of valva. Cucullus divided into two lobes: wide triangular lobe where sacculus meets cucullus, and another longer, distally expanded lobe in costal side. Digitate process very long and narrow, more than 8 times as long as wide, distally slightly wider than in narrowest point, with a few setae. Median plate of juxta with posteriorly directed large and wide pocket at dorsal side. Juxta lobes medially strongly produced, median margin straight and distinctly sclerotized, distal margin with few 

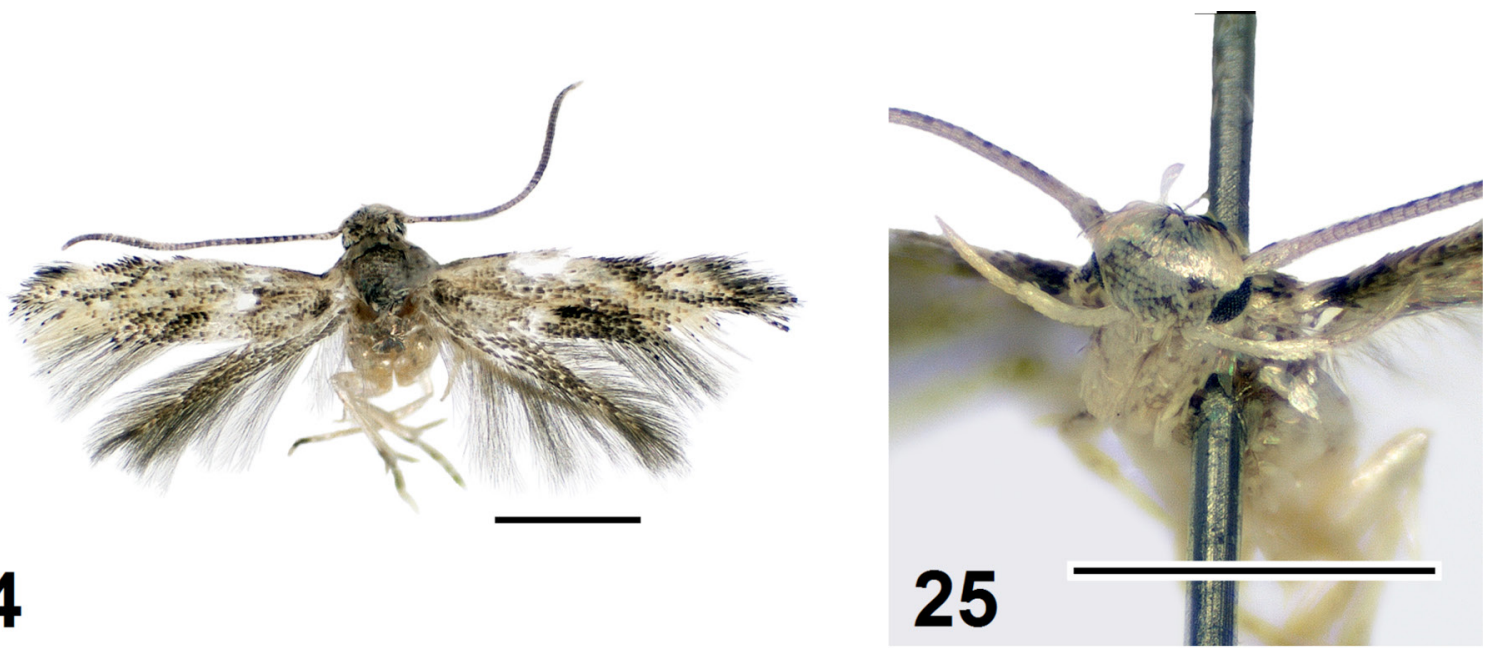

24

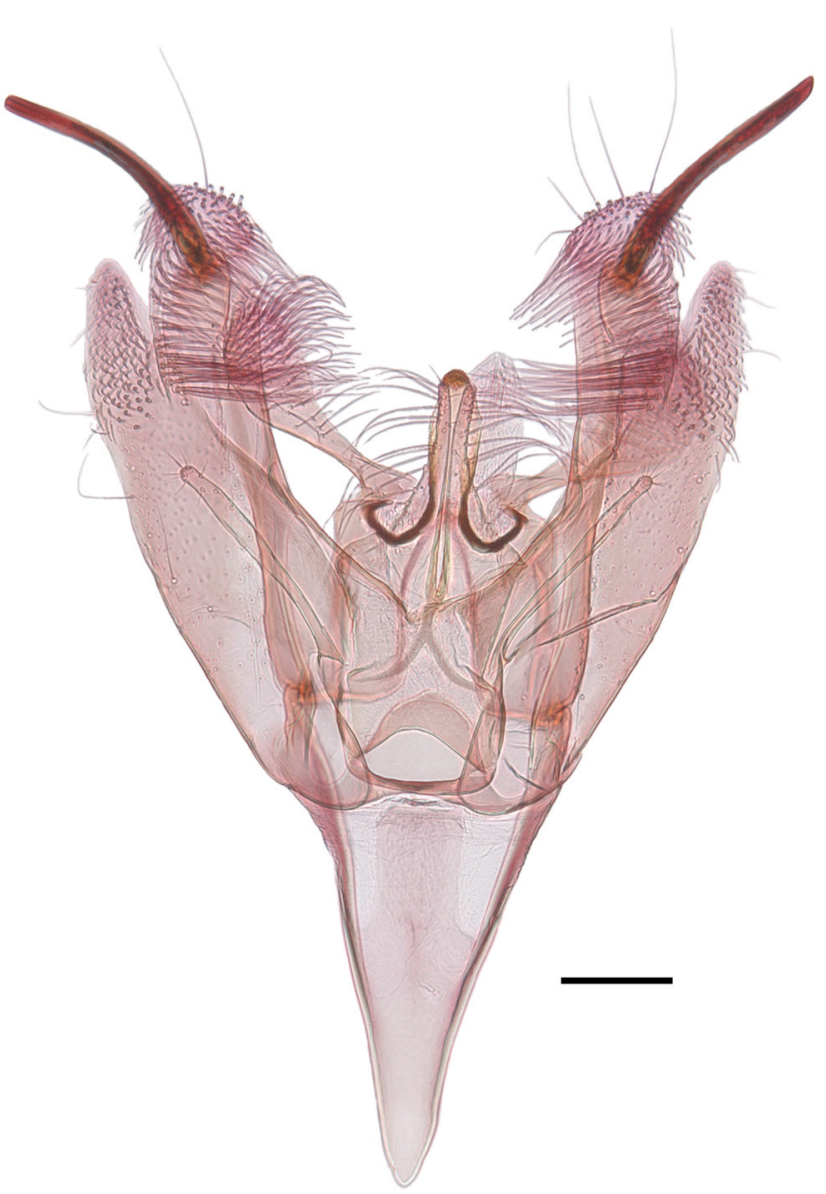

Figs 24-27. Elachista pellineni Sruoga \& Kaila sp. nov., holotype, đ̊ (MZH VS2/23.11.18). 24. Adult. 25. Head, latero-frontal view. 26. General view of male genitalia (phallus removed). 27. Phallus. Scale bars: $24-25=1 \mathrm{~mm} ; 26-27=0.1 \mathrm{~mm}$. 

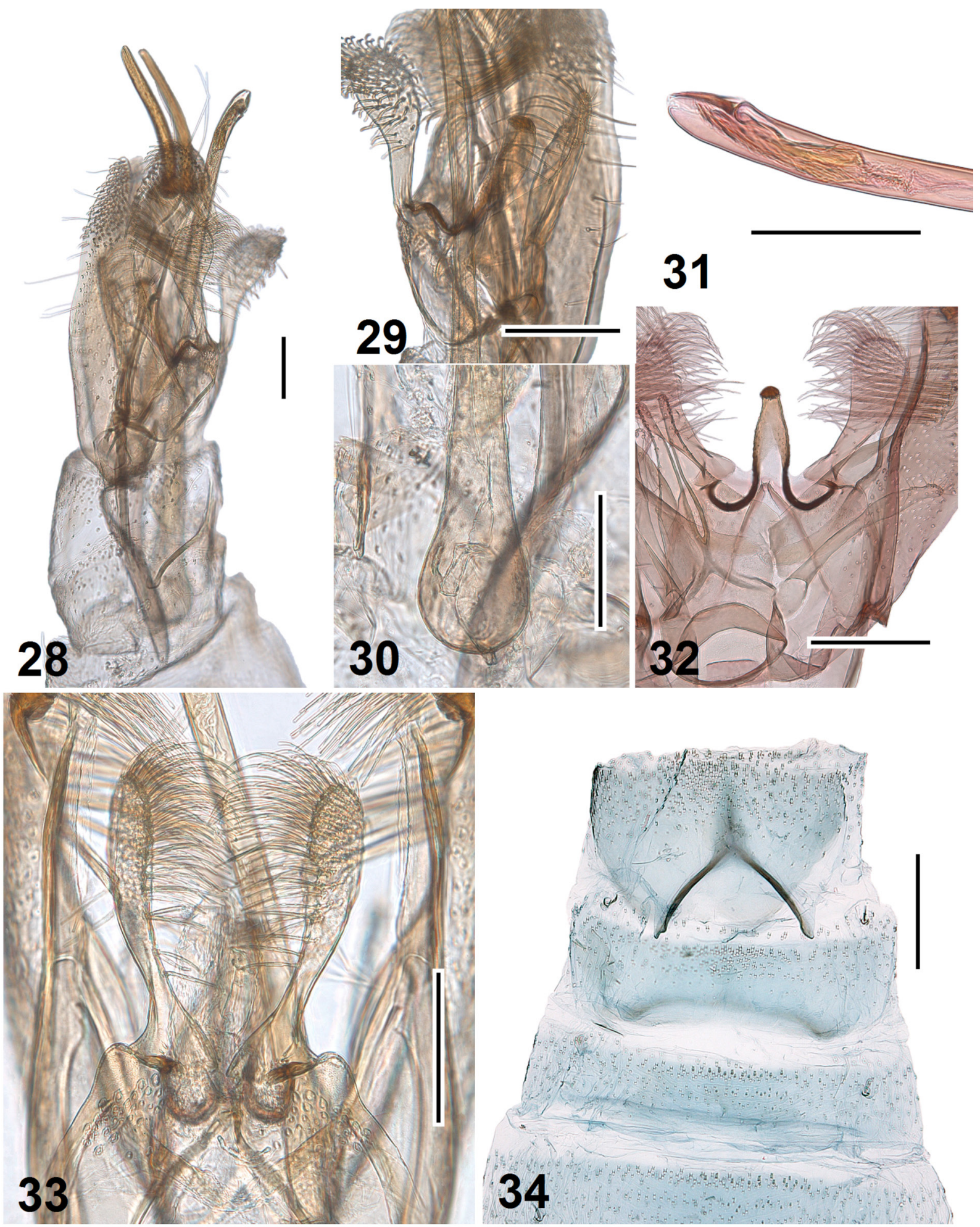

Figs 28-34. Elachista pellineni Sruoga \& Kaila sp. nov., male genitalia, holotype, $ð$ (MZH VS2/23.11.18, in glycerol before permanent mounting in Euparal). 28. Lateral view. 29. Juxta, lateral view. 30. Proximal part of phallus. 31. Distal part of phallus. 32. Juxta region and gnathos. 33. Uncus lobes, dorsal view. 34. Distal part of abdomen, dorsal view. Scale bars $=0.1 \mathrm{~mm}$. 


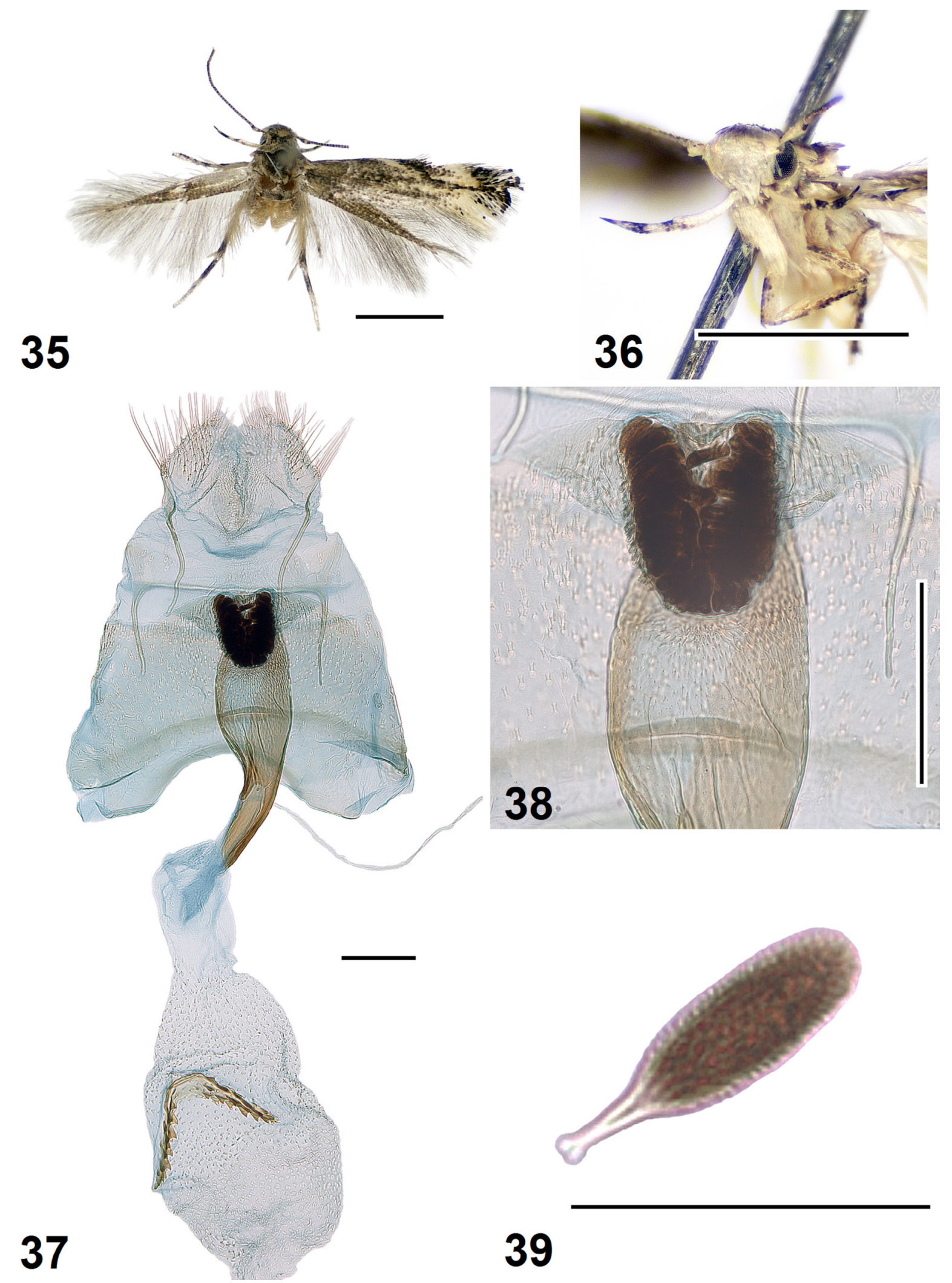

Figs 35-39. Elachista pellineni Sruoga \& Kaila sp. nov., paratype, $q$ (MZH VS1/24.11.18). 35. Adult. 36. Head, latero-frontal view. 37. Female genitalia. 38. Antrum. 39. Scale from antrum. Scale bars: $35-36=1 \mathrm{~mm} ; 37-38=0.1 \mathrm{~mm} ; 39=0.03 \mathrm{~mm}$. 
tiny setae and dorsally directed group of long hair-like scales. Vinculum long, v-shaped, tapered to broad saccus. Phallus about 1.5 length of valva, basally dilated, weakly bent; caecum short, rounded with sclerotized ridge forming two small lobes; vesica with one large, bent cornutus, and with large group of slender spines, increasing in size distally.

\section{Female}

External CHARACters (Figs 35-36). Forewing length $2.6 \mathrm{~mm}$; wingspan $5.8 \mathrm{~mm}(\mathrm{n}=1)$. Similar to male, but flagellum thinner and darker, forewing darker.

Female genitalia (Figs 37-39). Papilla analis short and rounded, setose; setae on latero-basal part distinctly longer. Apophyses weakly curved, apophysis posterioris slightly longer than apophysis anterioris. Integument between sterna 7 and 8 folded as wide invagination densely filled by small dark scales in central part. Anterior margin of abdominal segment 7 reinforced, tergum 7 with distinct semicircular invagination. Antrum-colliculum complex evenly bent, tapering, inner side posteriorly with dense internal spines and a few longitudinal folds. Ductus bursae short and wide, membranous. Ductus seminalis incepted at the border of colliculum and membranous part of ductus bursae. Corpus bursae with dense internal spines. Signum boomerang-shaped, medially broadest, margins dentate laterally.

\section{Biology}

Unknown.

\section{Flight period}

Based upon three specimens available, adults fly in May and September.

\section{Distribution}

So far this species is known only from northern Thailand.

Elachista capricornis Sruoga \& Kaila sp. nov. urn:1sid:zoobank.org:act:F8E10FCC-EE74-4D48-AA41-A70E8D882B7E

Figs $40-50$

\section{Diagnosis}

Elachista capricornis Sruoga \& Kaila sp. nov. is a small species with peculiarly coloured forewings (Fig. 40) and a dorsoventrally flattened head. In wing pattern and male genitalia, the new species is comparable to E. heteroplaca (for illustrations, we refer to Kaila 1998: figs 1-5), E. oryx Sruoga \& Kaila sp. nov. and E. pellineni Sruoga \& Kaila sp. nov., known from the same locality as E. capricornis Sruoga \& Kaila sp. nov. However, the new species is distinguished most easily by its larger, distinctly curved, S-shaped spine of valva.

\section{Etymology}

The species name is derived from the Latin 'capricornis' (a goat-antelope with short sharp horns) in reference to the horn-like spines of valvae.

\section{Type material}

\section{Holotype}

THAILAND • O’ $^{\prime}$ Lampang, Muban Phichai; $18^{\circ} 18^{\prime} 15^{\prime \prime}$ N, 99³1’06" E; 8 Jan. 2014; M.J. Pellinen leg.; MZH VS2/21.11.18. 

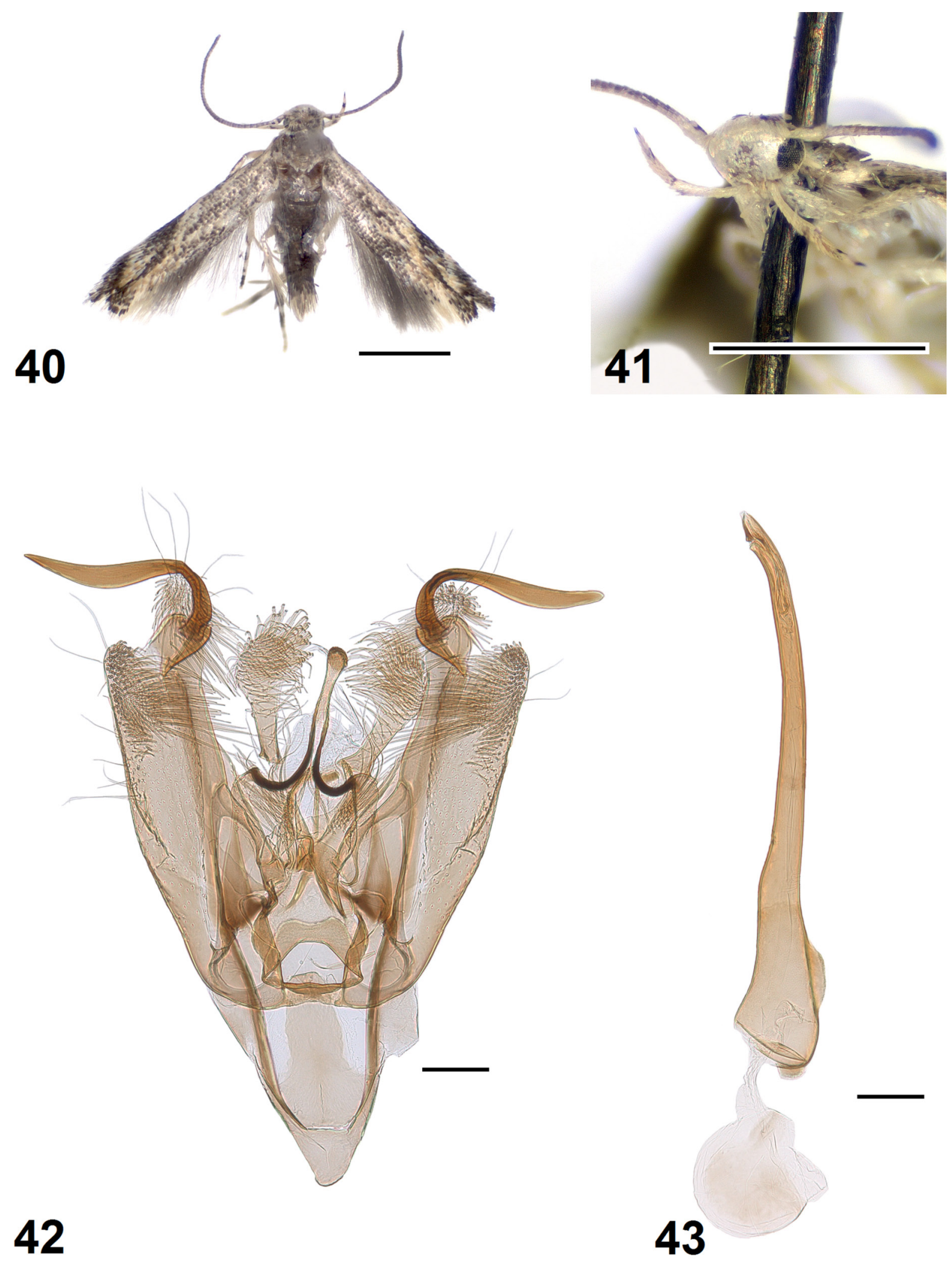

Figs 40-43. Elachista capricornis Sruoga \& Kaila sp. nov. 40-41. Male paratype. 40. Adult. 41. Head, latero-frontal view. 42-43. Holotype, $\widehat{\partial}$ (MZH VS2/21.11.18). 42. General view of male genitalia (phallus removed). 43. Phallus. Scale bars: $40-41=1 \mathrm{~mm} ; 42-43=0.1 \mathrm{~mm}$. 
Paratypes

THAILAND • 1 ऊं; same locality as for holotype; 12 Jan. 2012; M.J. Pellinen leg.; MZH VS2/22.11.18 • $1 \delta^{\lambda}$; same locality as for holotype; 23 Jan. 2013; M.J. Pellinen leg.; MZH VS3/22.11.18 • 1 §;; same

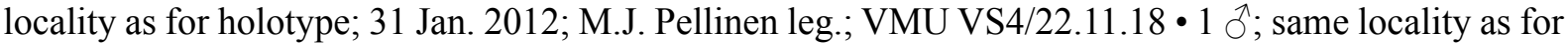
holotype; 23 Feb. 2019; M.J. Pellinen leg.; MZH 6178.

\section{Description}

\section{Male}

EXTERNAL CHARACTERS (Figs 40-41). Forewing length 2.5-2.8 mm; wingspan 5.6-6.2 mm ( $\mathrm{n}=4)$. Head: frons shiny, creamy white; vertex and neck tuft brownish white, some scales with dark brown tips; labial palpus upwards curved, about 1.6 times as long as width of head, creamy white, third segment medially with few dark brown scales on outer side; scape creamy white below, with few dark brown scales above, without pecten; flagellum creamy white below, greyish brown above, weakly annulated with paler rings, somewhat serrate in distal $1 \frac{1}{2}$, last flagellomere creamy white. Thorax and tegula intermixed with greyish brown and dark brown scales. Forewing: ground colour greyish brown, costa narrowly dark except at $1 / 5$ where indistinctly delimited oblique white streak and at $2 / 5$ where larger oblique white streak almost reaches fold; in the middle of wing at fold dark brown spot formed of slightly raised scales; tornal area whitish; narrow longitudinal blackish brown stripe to apex of wing; fringe scales brownish grey, fringe line blackish brown. Hindwing and its fringe scales brownish grey.

MaLe Genitalia (Figs 42-50). Uncus lobes widely apart from each other, elongate, basally dilated, distally distinctly broadened, ventral surface densely covered with long, hair-like scales. Tegumen short, anterior margin dorsomedially strongly and widely indented, almost meeting posterior margin. Basal arms of gnathos very long, basally strongly melanized, and strongly bent towards posterior direction, apically fused and covered with several tiny spines; spinose knob small, spinose area directed apically. Costa of valva weakly concave; from distal fold of costa long, strongly sclerotized spine, length of which nearly $1 / 2$ of that of valva. Cucullus divided into two lobes: wide triangular lobe where sacculus meets cucullus, and another slightly longer, narrow lobe in costal side. Digitate process short and wide, triangular, devoid of setae. Median plate of juxta with two pockets: anteriorly directed very small, triangular pocket at ventral side, and posteriorly directed large and wide one at dorsal side. Juxta lobes medially strongly produced, median margin straight and distinctly sclerotized, distal margin with few tiny setae and dorsally directed large group of long hair-like scales. Vinculum long, v-shaped, tapered to short and broad saccus. Phallus about 1.25 length of valva, basally dilated, bent at basal $1 / 4$ and more distinctly bent at apical $1 / 10$; caecum short, rounded; proximal part of phallus with sclerotized ridge forming two lobes, one small, nipple-shaped at basal end of phallus, and larger one, prolonged at basal $1 / 10$ of phallus; vesica with group of minute spines and one long, bent cornutus.

\section{Female}

Unknown.

\section{Biology}

Unknown. The specimens have been attracted by artificial light.

\section{Flight period}

Based upon specimens available, adults fly in January.

\section{Distribution}

So far this species is known only from northern Thailand. 


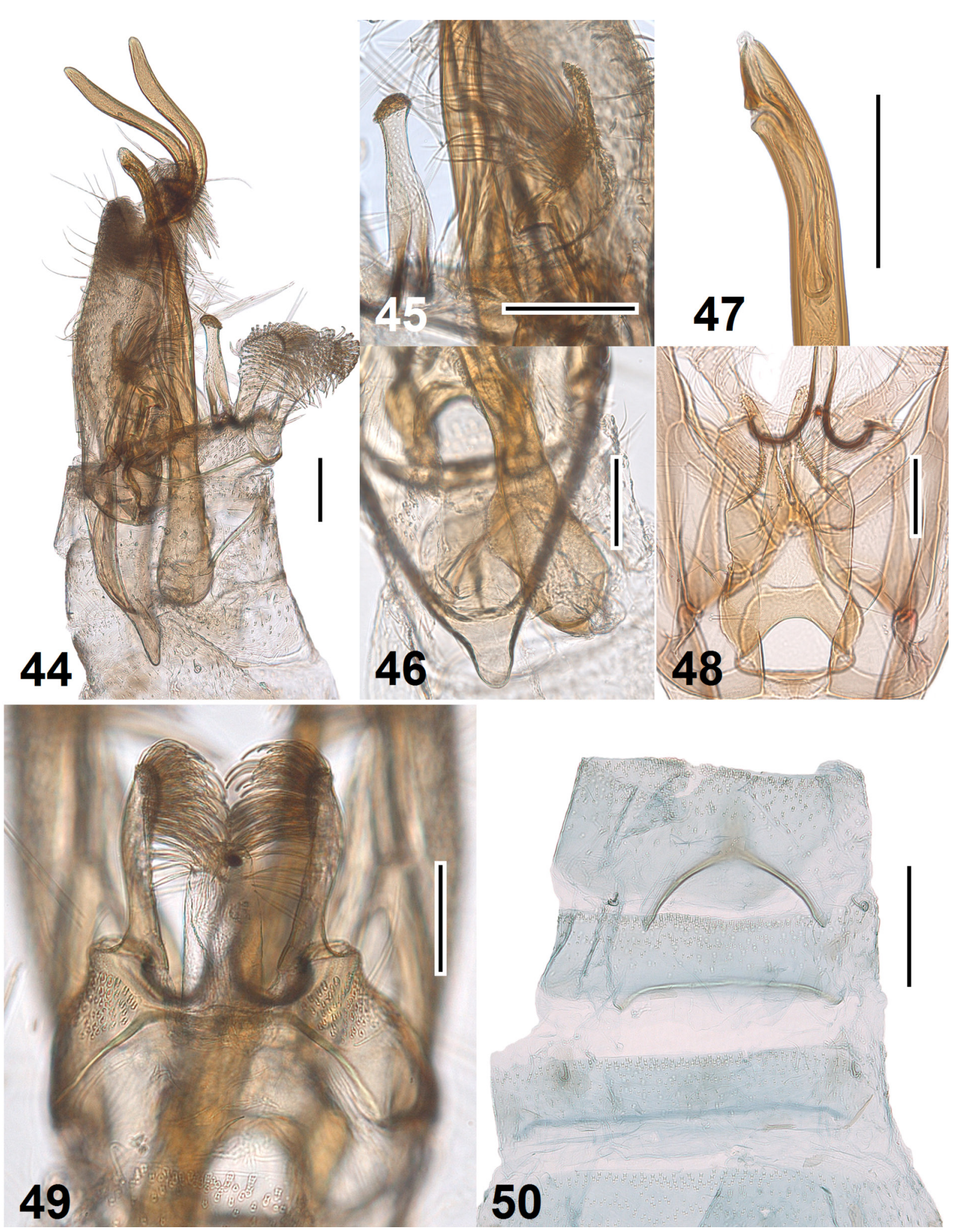

Figs 44-50. Elachista capricornis Sruoga \& Kaila sp. nov., male genitalia. 44-46, 48-49. Paratype, $\widehat{\jmath}$ (MZH VS2/22.11.18, in glycerol before permanent mounting in Euparal). 44. Lateral view. 45. Juxta and gnathos, lateral view. 46. Proximal part of phallus. 47, 50. Holotype, $\overbrace{}^{\Uparrow}$ (MZH VS2/21.11.18, in glycerol before permanent mounting in Euparal). 47. Distal part of phallus. 48. Juxta region. 49. Uncus lobes, dorsal view. 50. Distal part of abdomen. Scale bars $=0.1 \mathrm{~mm}$. 


\section{Elachista phichaiensis Sruoga \& Kaila sp. nov. urn:1sid:zoobank.org:act:769ABFE1-689B-479D-A613-8162CBAE599B}

Figs $51-58$

\section{Diagnosis}

Elachista phichaiensis Sruoga \& Kaila sp. nov. is a small species with peculiarly coloured forewings (Fig. 51) and a dorsoventrally flattened head. In wing pattern and male genitalia, the new species is most similar to E. albrechti Kaila, 1998 (for illustrations, we refer to Kaila 1998: figs 12-17), known from Nepal. However, the new species is easily distinguished by features of the male genitalia. The main differences between E. phichaiensis Sruoga \& Kaila sp. nov. and E. albrechti are: (1) in E. phichaiensis Sruoga \& Kaila sp. nov. the digitate process is long and slender, in E. albrechti it is short and wide; (2) the spinose knob of gnathos in E. phichaiensis Sruoga \& Kaila sp. nov. is not indented distally and spinose area is not separated by membranous area as it is in E. albrechti; (3) in E. phichaiensis Sruoga \& Kaila sp. nov. the indentation of cucullus about $1 / 3$ of the width of the distal lobe of cucullus, in E. albrechti the indentation of cucullus is as wide as the distal lobe of cucullus; (4) in E. phichaiensis Sruoga \& Kaila sp. nov. the saccus is very short, as long as its width, in E. albrechti it is slender and long, three times as long as wide; (5) the vesica in E. phichaiensis Sruoga \& Kaila sp. nov. is with cornuti, in E. albrechti without.

\section{Etymology}

In reference to the host location, Phichai, where the holotype was collected.

\section{Type material}

\section{Holotype}

THAILAND • $\widehat{O}^{\top}$; Lampang, Muban Phichai; $18^{\circ} 18^{\prime} 15^{\prime \prime}$ N, 99³1'06" E; 21 Nov. 2012; M.J. Pellinen leg.; MZH VS3/2.11.18.

\section{Description}

Male

EXTERNAL CHARACTERS (Figs 51-52). Forewing length $2.7 \mathrm{~mm}$; wingspan $6 \mathrm{~mm}(\mathrm{n}=1)$. Head: frons shiny, creamy white; vertex and neck tuft whitish brown, some scales with dark brown tips; labial palpus upwards curved, diverging, about 1.4 times as long as width of head, creamy white, third segment with few dark brown scales; scape creamy white below, with few dark brown scales above, without pecten; flagellum creamy white below, greyish brown above, weakly annulated with paler rings. Thorax and tegula intermixed with greyish brown and creamy brown scales. Forewing: ground colour varying from creamy to a mixture of rusty and dark grey scales, costa dark brown except medially from where oblique pale ochreous streak extend to fold, and in distal $3 / 4$ where it is creamy to varying extent; in the middle of wing at fold dark brown spot formed of slightly raised scales; fringe scales brownish grey, fringe line blackish brown. Hindwing and its fringe scales brownish grey.

MaLe Genitalia (Figs 53-58). Uncus lobes widely apart from each other, elongate, relatively short, slightly longer than its width, ventral surface densely covered with short, thick scales. Basal arms of gnathos very long, basally strongly melanized, and strongly bent towards posterior direction, apically fused; spinose knob medium sized, oval. Costa of valva weakly concave; basal fold of costa meets distal fold at $2 / 5$ from base. Cucullus medially deeply incised, thus divided into two lobes: wide triangular lobe where sacculus meets cucullus, and another very large distal lobe. Digitate process long and slender, $1 / 3$ length of valva and about 13 times as long as its width, distally with few short setae. Juxta lobes large, about $2 / 5$ length of valva, medially produced as curved horn, median margin with short setae, distal margin with row of very long dorsally directed hair-like scales. Vinculum with broad median ridge, 

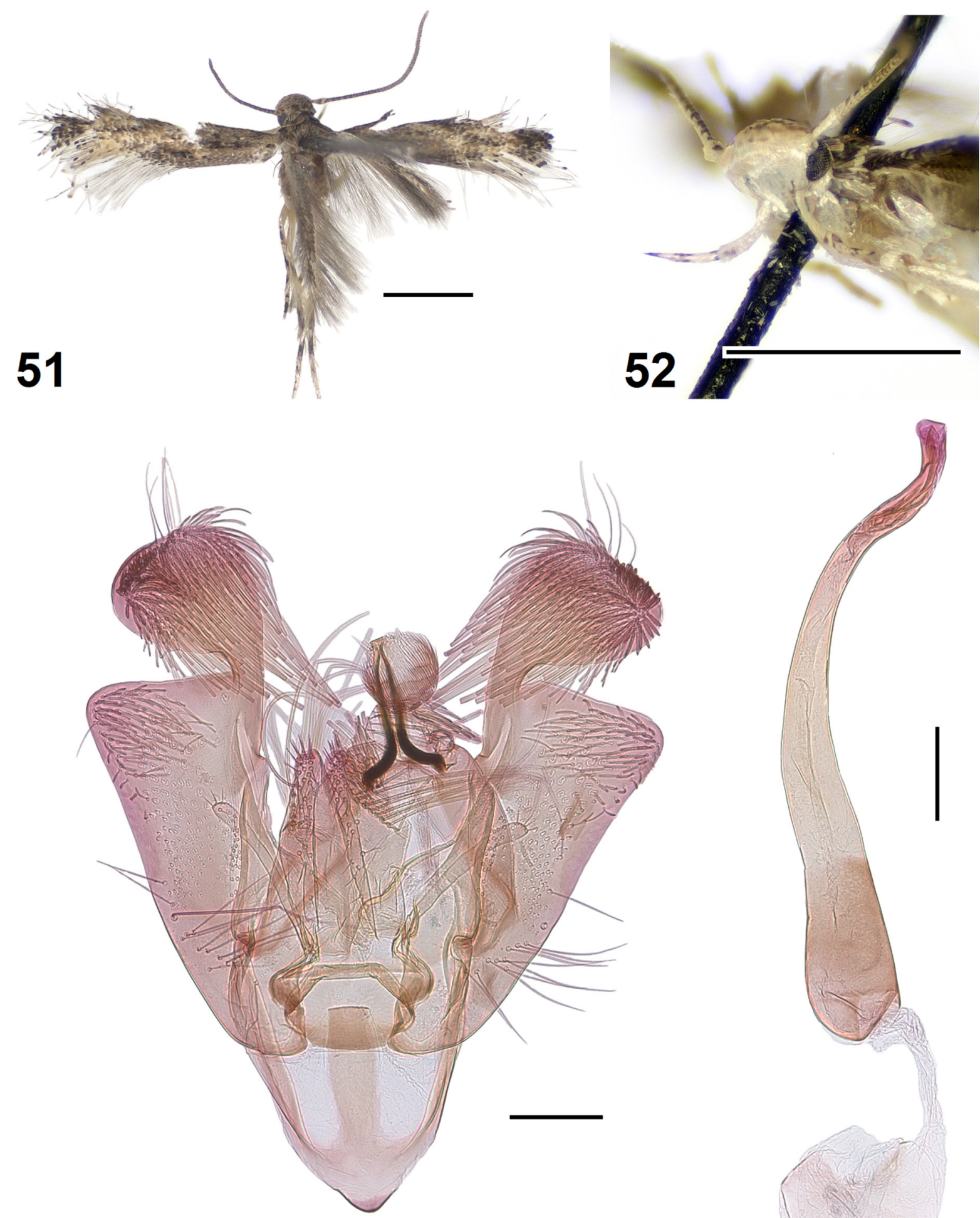

53

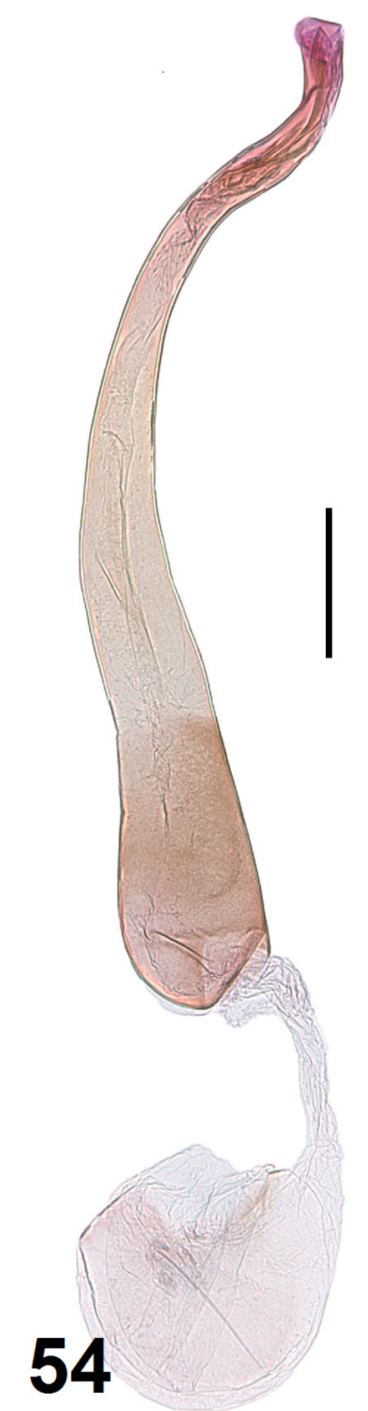

Figs 51-54. Elachista phichaiensis Sruoga \& Kaila sp. nov., holotype, $\widehat{\jmath}$ (MZH VS3/2.11.18). 51. Adult. 52. Head, latero-frontal view. 53. General view of male genitalia (phallus removed). 54. Phallus. Scale bars: $51-52=1 \mathrm{~mm} ; 53-54=0.1 \mathrm{~mm}$. 


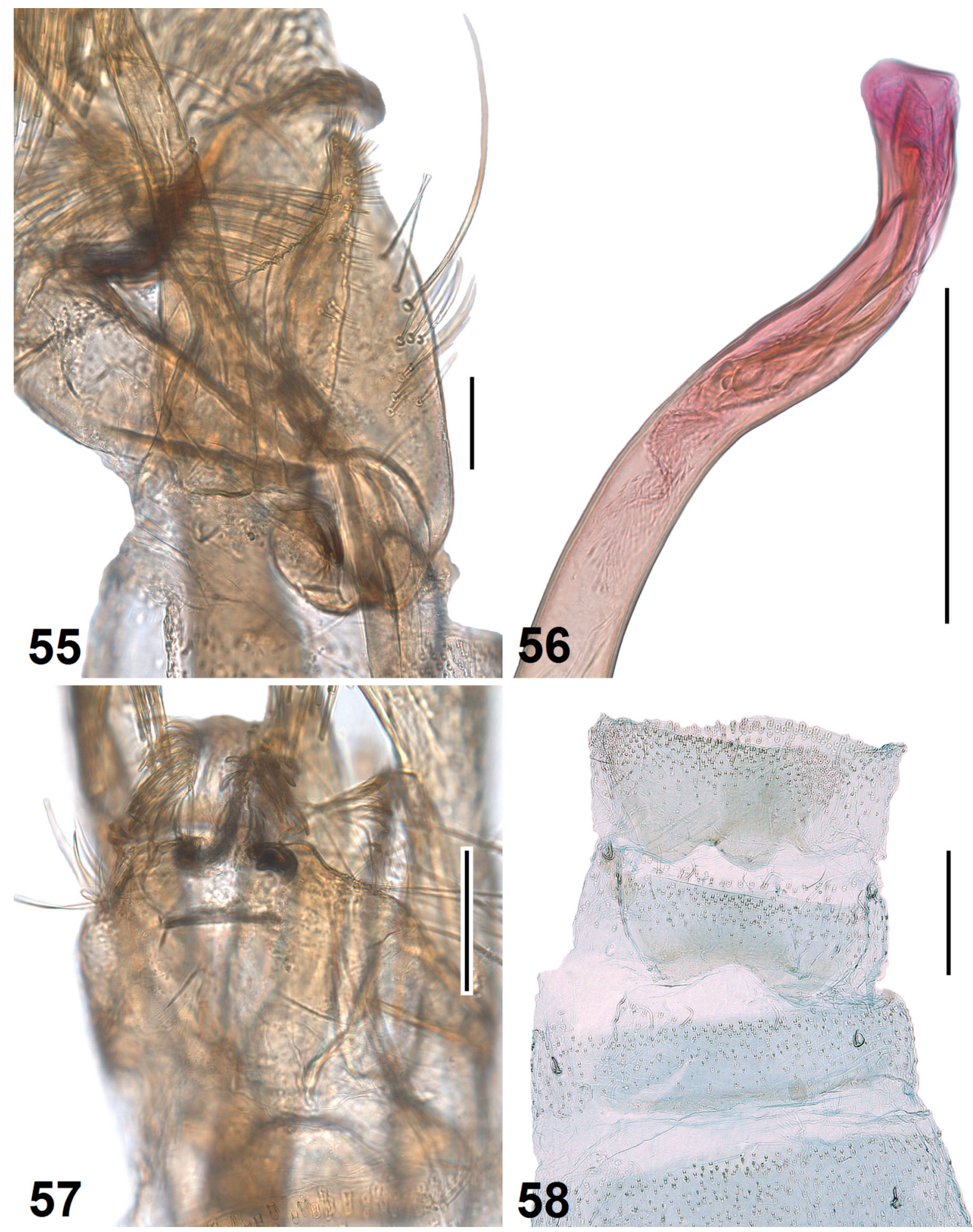

Figs 55-58.Elachistaphichaiensis Sruoga \& Kailasp.nov., malegenitalia, holotype, $\bigcirc^{\lambda}$ (MZHVS3/2.11.18, in glycerol before permanent mounting in Euparal). 55. Juxta, lateral view. 56. Distal part of phallus. 57. Uncus lobes, dorsal view. 58. Distal part of abdomen. Scale bars $=0.1 \mathrm{~mm}$. 
tapered to short and broad saccus. Phallus about 1.26 length of valva, evenly bent from basal $1 / 3$; vesica with group of minute spines and three long, bent cornuti.

\section{Female}

Unknown.

\section{Biology}

Unknown. The specimen was collected by artificial light.

\section{Flight period}

The only known specimen was captured in November.

\section{Distribution}

So far this species is known only from northern Thailand.

\section{Remarks}

The wings in the holotype is somewhat rubbed, therefore the description of external characters is approximate.

Elachista species $\mathrm{Nr}$ VS3/29.03.19

Figs 59-62

\section{Diagnosis}

Elachista species $\mathrm{Nr}$. VS3/29.03.19 is a small species with peculiarly coloured forewings and a dorsoventrally flattened head. In wing pattern this species is comparable to E. heteroplaca (for illustrations, we refer to Kaila 1998: figs 1-5), E. lorigera Meyrick, 1921 (for illustrations, we refer to Kaila 1998: figs 6-7), E. albrechti (for illustrations, we refer to Kaila 1998: figs 12-17) and Thailandese species of Elachista saccharella species group described here as new (comprising E. oryx Sruoga \& Kaila sp. nov., E. pellineni Sruoga \& Kaila sp. nov., E. capricornis Sruoga \& Kaila sp. nov. and E. phichaiensis Sruoga \& Kaila sp. nov.). Female genitalia of $E$. species Nr. VS3/29.03.19 are distinctive with the long, narrow, almost straight signum and corpus bursae devoid of internal spines.

\section{Material examined}

THAILAND • 1 क; Lampang, Phichai; 18²0’ N, 99³2' E; 1-30 Oct. 2007; M.J. Pellinen leg.; MZH VS3/29.03.19.

\section{Description}

\section{Female}

EXTERNAL CHARACTERS (Figs 59-60). Forewing length $3.4 \mathrm{~mm}$; wingspan $7.3 \mathrm{~mm}(\mathrm{n}=1)$. Head: frons shiny, creamy white; vertex and neck tuft brownish white, some scales with dark brown tips; labial palpus upwards curved, diverging, about 1.8 times as long as width of head, creamy white, third segment medially with few dark brown scales; scape creamy white below, with few dark brown scales above, without pecten; flagellum creamy white below, greyish brown above, annulated with paler rings, last flagellomere creamy white. Thorax grey brown. Forewing: ground colour greyish brown with scattered rusty brown scales, costa narrowly dark except at $1 / 3$ where indistinctly delimited oblique creamy white streak and at $2 / 3$ where larger oblique creamy white streak almost reaches fold; in the middle of wing at fold blackish brown spot formed of raised scales; tornal area creamy white; narrow longitudinal blackish 


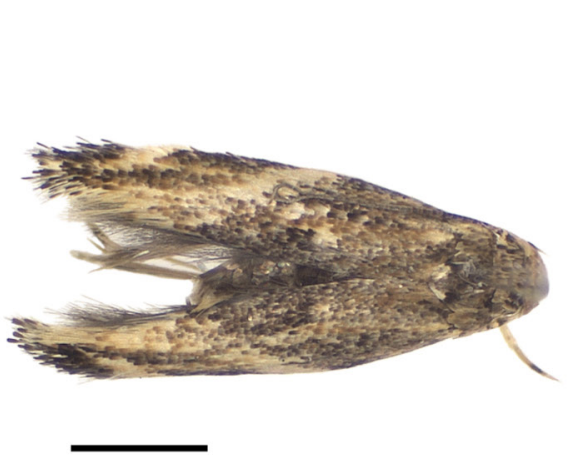

\section{9}
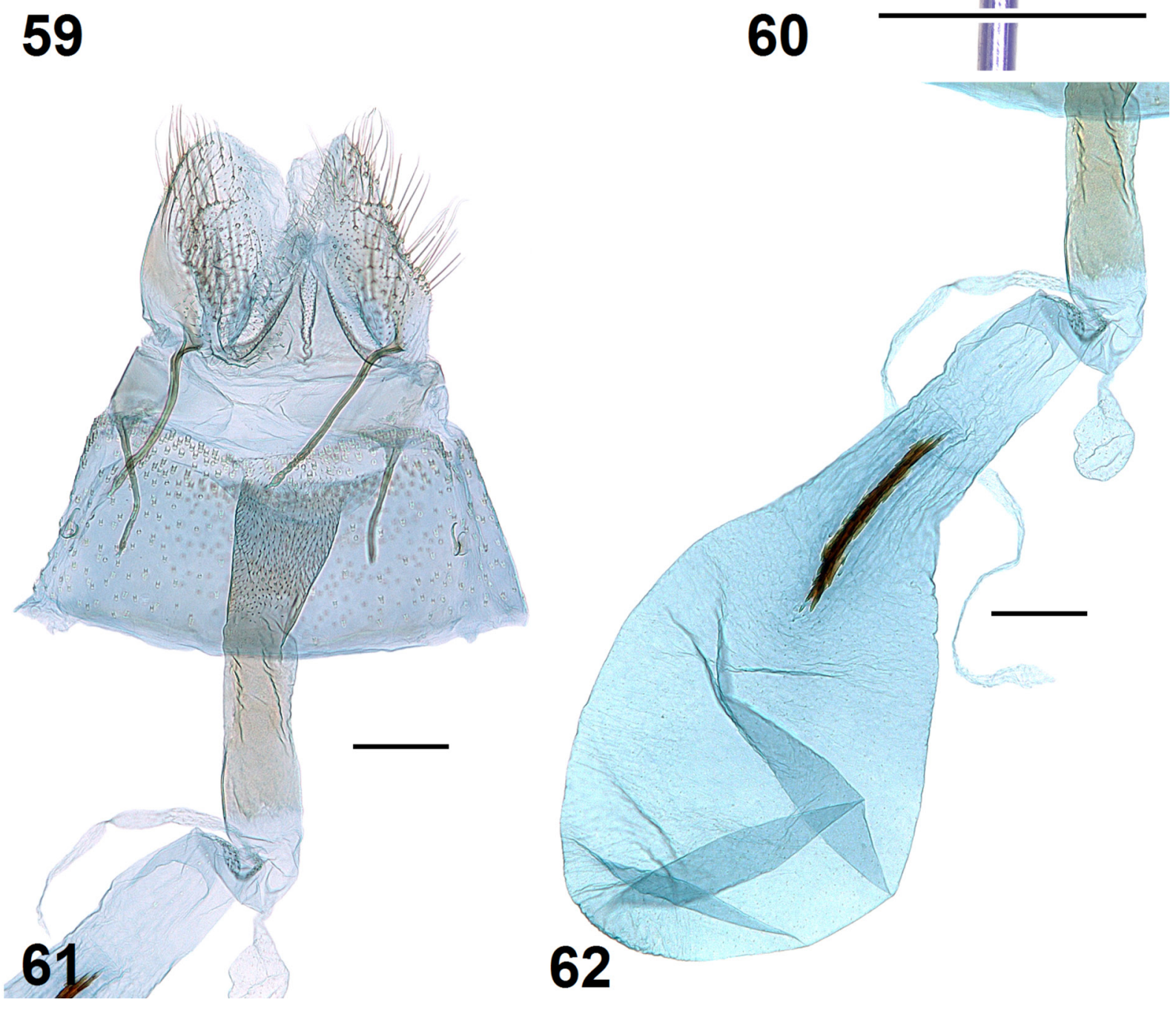

Figs 59-62. Elachista sp. (MZH VS3/29.03.19). 59. Adult female. 60. Head, latero-frontal view. 61. Female genitalia, caudal part. 62. Ductus and corpus bursae. Scale bars: $59-60=1 \mathrm{~mm}$; $61-$ $62=0.1 \mathrm{~mm}$. 
brown stripe to apex of wing; fringe scales brownish grey, fringe line dark brown. Hindwing and its fringe scales brownish grey.

Female genitalia (Figs 61-62). Papilla analis longer than wide, setose. Apophysis posterioris slightly longer than apophysis anterioris. Ostium bursae situated at posterior margin of sternum 7, occupying $2 / 5$ of the space between apophyses anteriores, dorsal wall covered with minute spines. Antrum large, about 1.5 times longer than wide, inwardly densely covered with small spines. Colliculum weakly sclerotized, as long as antrum. Ductus bursae membranous, gradually widened towards corpus bursae with which it is incepted without distinct border; corpus bursae without internal spines. Signum long, narrow, almost straight, with a few rows of teeth.

\section{Male \\ Unknown.}

\section{Biology}

Unknown. The specimen was collected by artificial light.

\section{Flight period}

The only known specimen was captured in December.

\section{Distribution}

So far this species is known only from northern Thailand.

\section{Remarks}

This female singleton externally resembles several other species found at the same site. It may be conspecific with some other species of Elachista albrechti-heteroplaca species group, now only known from males. Therefore, this taxon is documented but not named pending availability of additional male material.

Elachista loeiensis Sruoga \& Kaila sp. nov. urn:1sid:zoobank.org:act:C7B51906-9FE4-4AA2-9220-C91DB0BF31F7

Figs 63-66

\section{Diagnosis}

The wing pattern of this species is hardly distinguishable from many others of the Elachista freyerella species group. It is one of the six known eastern Palaearctic or Oriental species of the $E$. freyerella species group whose phallus contains a cornutus. These species can be divided into two groups: species with the cornutus elongate, and species with the cornutus short and arrow-shaped. Elachista spiculifera Meyrick, 1922 described from India, E. cornutifera Sruoga, 1995 described from Russian Far East, E. nipponicella Sugisima, 2006 described from Japan and E. loeiensis Sruoga \& Kaila sp. nov. belongs to the species group with an elongate cornutus. They can be separated from each other as follows: the distal spine of the cucullus is very robust in E. spiculifera (cf. Sruoga \& Diškus 2006), slender in the three other species. The phallus is distally markedly bent in E. cornutifera (cf. Sruoga 1995) and E. nipponicella (cf. Sugisima 2006), evenly bent from middle to apex in E. loeiensis Sruoga \& Kaila sp. nov. Elachista stichospora Meyrick, 1932 and E. siamensis Sruoga \& Kaila sp. nov. have a short, arrow-shaped cornutus. They can be separated from each other as follows: the distal spine of $E$. stichospora is evenly bent towards cucullus, straight in E. siamensis Sruoga \& Kaila sp. nov.; the phallus is very narrow and distinctly longer than valva, with a small tooth near apex in E. stichospora (Sruoga \& Diškus 2006); the phallus is broader, and approximately as long as the valva in E. siamensis Sruoga \& Kaila sp. nov. 


\section{Etymology}

In reference to the host location, Loei Province, northeastern Thailand, where the holotype was collected.

\section{Type material}

\section{Holotype}

THAILAND • O'; Loei Province, Phu Luang Wildlife Sanctuary; 700-900 m; 8-14 Oct. 1984; Karsholt, Lomholdt and Nielsen leg.; ZMUC 2073.

\section{Description}

\section{Male}

EXternal CHARACTERS (Figs 63-64). Forewing length $2.6 \mathrm{~mm}$; wingspan $5.8 \mathrm{~mm}(\mathrm{n}=1)$. Head: frons shiny, creamy white; labial palpus upwards curved, diverging, about two times as long as width of head; antenna greyish brown, basal articles weakly annulated with paler rings; pecten present as a few short stiff seta-like scales at base of scape. Forewing ground colour pale greyish white, powdered with greyish brown-tipped scales; distal half of wing darker than basal; fringe scales greyish brown. Hindwing and its fringe scales greyish brown.

Male genitalia (Figs 65-66). Uncus lobes narrow and long, apically curved and tapered to pointed apex; ventral surface covered with mixture of short and thick, and long and slender setae. Basal arms of gnathos reinforced, spinose knob about 1.7 times as long as wide. Valva broadest in basal part; sacculus weakly concave medially, distally with stout spine; cucullus neither expanded nor produced towards costa, tip almost right-angled; basal fold of costa extended to $2 / 3$ of valva, where it meets distal fold forming broad indistinct hump. Median plate of juxta about 2.3 times as long as broad, proximal end formed as rounded sac; medial margin of juxta lobes strongly sclerotized; lobes elongate, broadest medially, tapered distally; ventral surface with few long and short setae. Digitate process $1 / 3$ length of valva, narrow, distally somewhat dilated and setose. Vinculum produced into very long parallel-sided blunt-tipped saccus. Phallus about 0.9 length of valva, narrow, broadest basally, curved at basal $1 / 4$ and more strongly at distal $1 / 3$; caecum dorsally with cusp-like lobe whose anterior margin is concave; vesica with one stout straight cornutus, about $1 / 6$ length of phallus.

\section{Female}

Unknown.

\section{Biology}

Unknown.

\section{Flight period}

The only known specimen was captured in October.

\section{Distribution}

So far this species is known only from northeastern Thailand.

\section{Remarks}

The holotype is in poor condition; the forewing and head are somewhat rubbed, the antennae are partly broken and therefore the description of external characters is incomplete. 


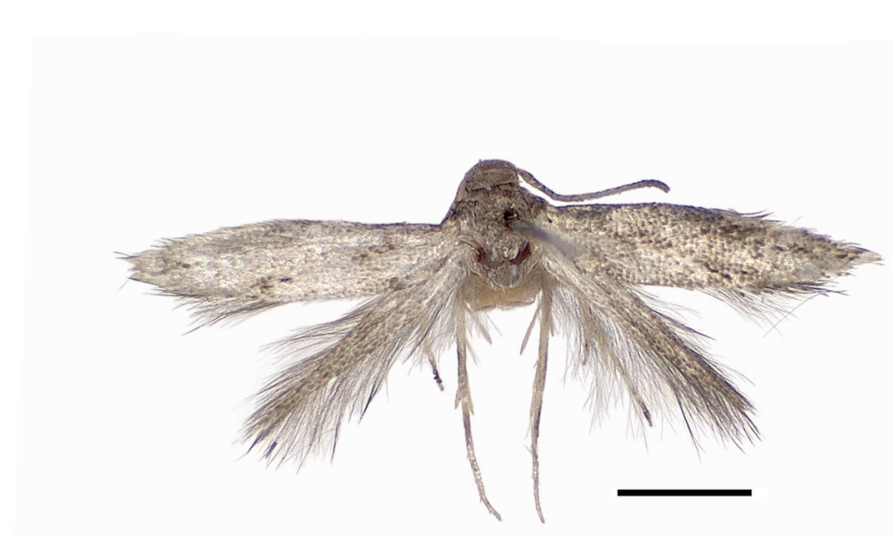

63
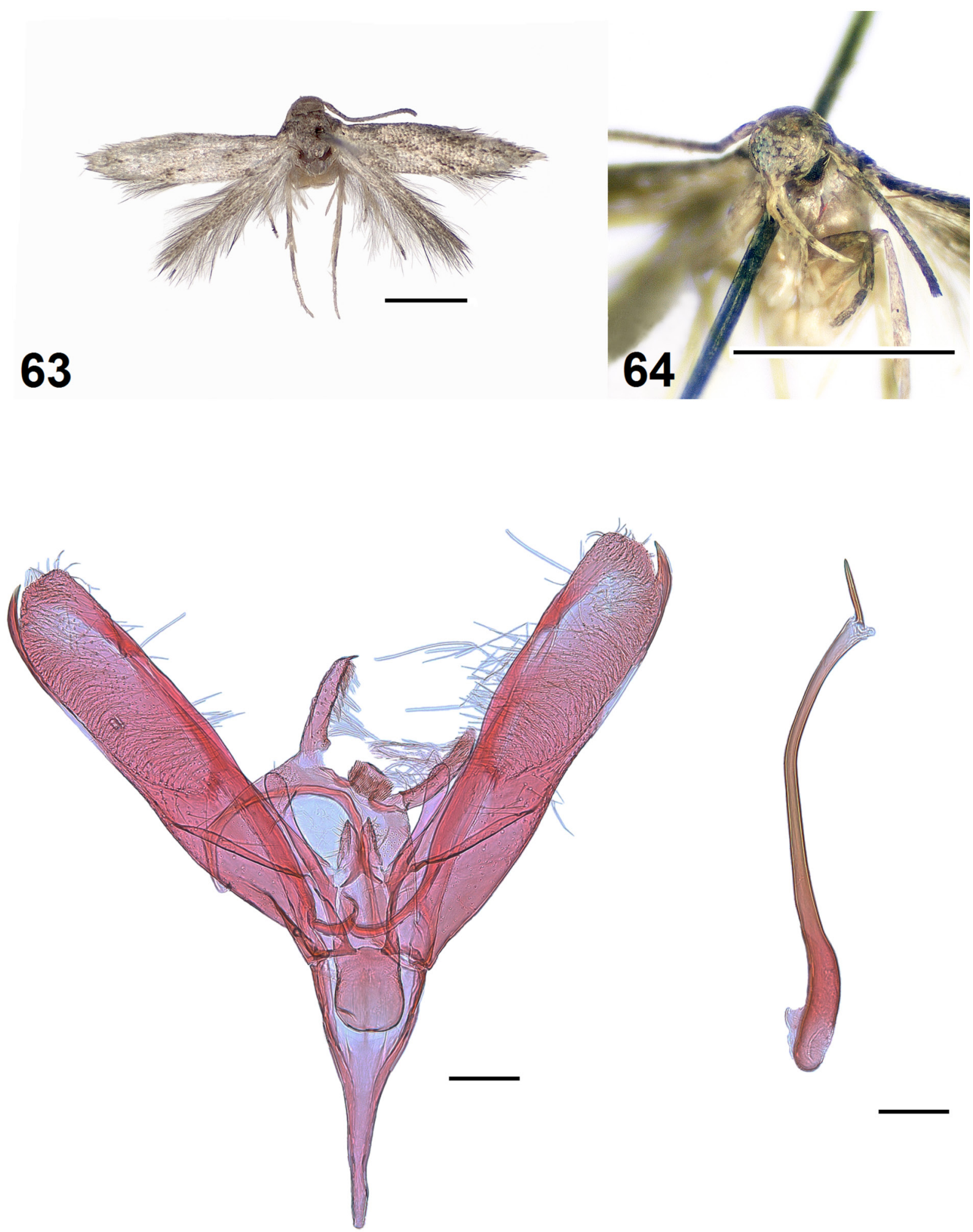

\section{5}

66

Figs 63-66. Elachista loeiensis Sruoga \& Kaila sp. nov., holotype, ð̊ (ZMUC 2073). 63. Adult male. 64. Head, latero-frontal view. 65. General view of male genitalia (phallus removed). 66. Phallus. Scale bars: $63-64=1 \mathrm{~mm} ; 65-66=0.1 \mathrm{~mm}$. 


\section{Elachista siamensis Sruoga \& Kaila sp. nov. urn:1sid:zoobank.org:act:ADD7FEC2-3FB8-46AB-838E-FAD6824D7520 \\ Figs $67-73$}

\section{Diagnosis}

In wing pattern and male genitalia, this species closely resembles Elachista loeiensis Sruoga \& Kaila sp. nov., known from northeastern Thailand. See diagnosis of E. loeiensis Sruoga \& Kaila sp. nov. for separation of the oriental and eastern palaearctic species of $E$. freyerella species group with a cornutus in the phallus.

\section{Etymology}

This species is named after Siam, the old name for Thailand, in reference to the type locality.

\section{Type material}

\section{Holotype}

THAILAND • O'; Nakhon Nayok Prov., Khao Yai Nat. Park; ca 700 m; 29 Sep.-6 Oct. 1984; Karsholt, Lomholdt and Nielsen leg.; ZMUC 2070.

\section{Paratypes}

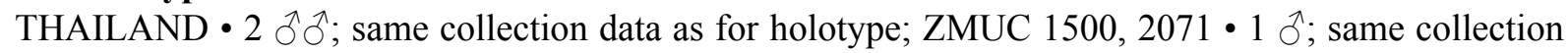
data as for holotype; VMU 1505 1 9 ; same collection data as for holotype; ZMUC $2075 \bullet 1$ ऽ; Loei Province, Phu Luang Wildlife Sanctuary; 700-900 m; 8-14 Oct. 1984; Karsholt, Lomholdt and Nielsen leg.; MZH 1504.

\section{Description}

\section{Male}

External CHARACTERs (Figs 67-68). Forewing length 2.6-2.8 mm; wingspan 5.8-6.3 mm $(\mathrm{n}=5$ ). Head: frons shiny, creamy white; vertex and neck tuft whitish brown, powdered with dark browntipped scales; labial palpus upwards curved, diverging, as long as width of head, creamy white above, whitish brown below; antenna greyish brown, weakly annulated with paler rings, somewhat serrate in distal $1 / 2$; pecten present as a few short stiff seta-like scales at base of scape. Thorax, tegula and ground colour of forewing formed from basally shortly creamy white and distally dark greyish brown making mottled appearance; plical spot elongate, blackish brown, at $1 / 2$ wing length on dorsal side of fold; discal spot elongate, blackish brown, at $2 / 3$ wing length in middle; fascia present as indistinct, creamy white, somewhat oblique band at $1 / 3$ wing length; creamy white costal and tornal spots indistinctly delimited; fringe scales grey-brown, fringe line blackish brown. Hindwing grey-brown, its fringe scales somewhat paler.

MaLe genitalia (Fig. 69). Uncus lobes narrow and long, apically curved and tapered to pointed apex; ventral surface covered with mixture of short and thick, and long and slender setae. Basal arms of gnathos reinforced, spinose knob about 1.6 times as long as wide. Valva broadest in basal part; sacculus weakly concave medially, distally with stout spine; cucullus neither expanded nor produced towards costa, tip rounded; basal fold of costa extended to $2 / 3$ of valva, where it meets distal fold forming broad distinct hump. Median plate of juxta two times as long as broad, proximal end formed as rounded sac; medial margin of juxta lobes strongly sclerotized; lobes short, broadest medially, tapered distally; ventral surface with few short setae. Digitate process $1 / 3$ length of valva, narrow, distally somewhat dilated and setose. Vinculum produced into long and narrow saccus. Phallus about 0.9 length of valva, narrow, broadest basally, almost straight; caecum dorsally with cusp-like lobe whose anterior margin is concave; vesica with one short cornutus that consists of weakly sclerotized elongate plate with one acute tooth. 

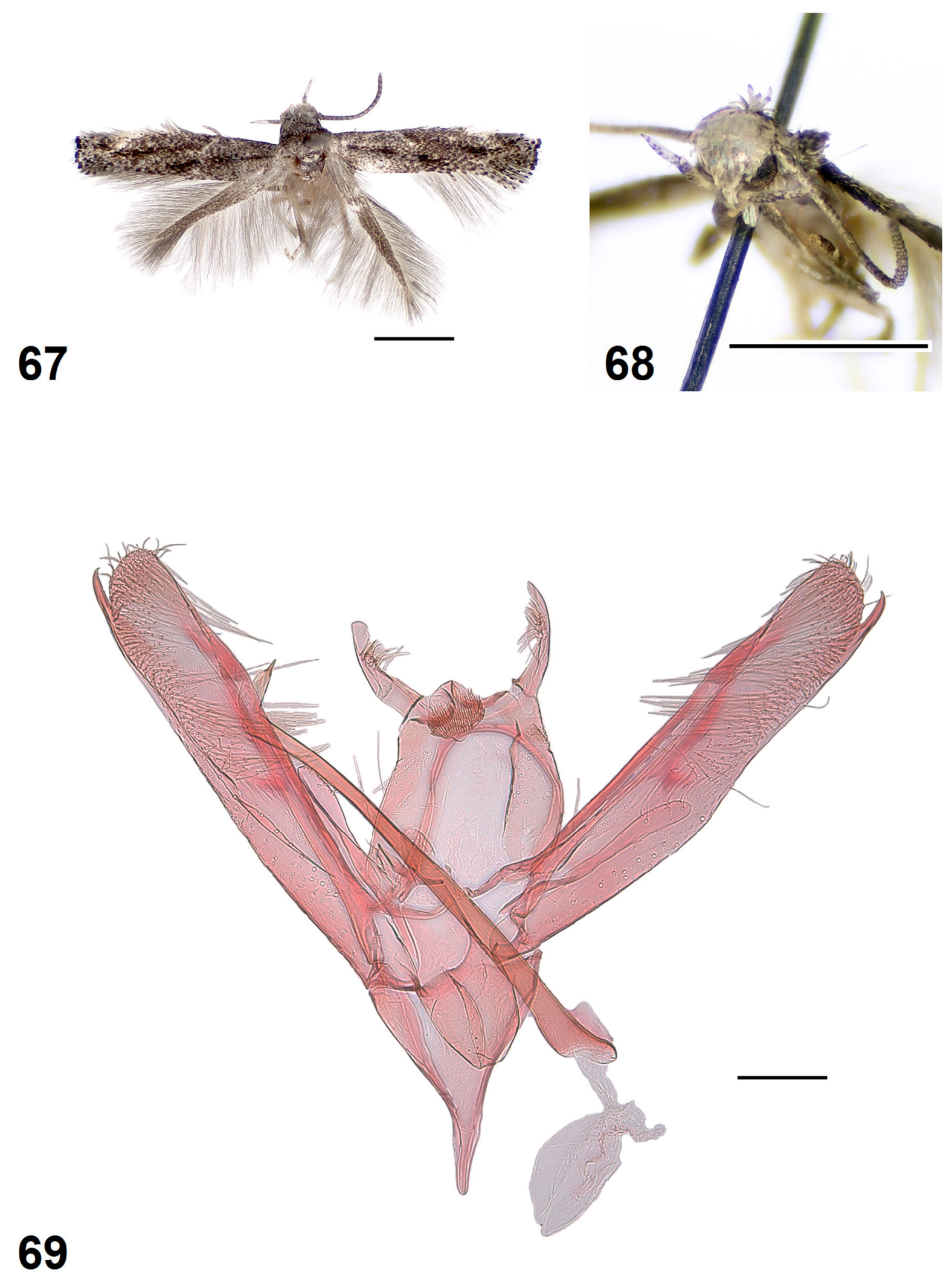

Figs 67-69. Elachista siamensis Sruoga \& Kaila sp. nov., holotype, $ð$ (ZMUC 2070). 67. Adult. 68. Head, latero-frontal view. 69. General view of male genitalia. Scale bars: $67-68=1 \mathrm{~mm} ; 69=0.1 \mathrm{~mm}$. 


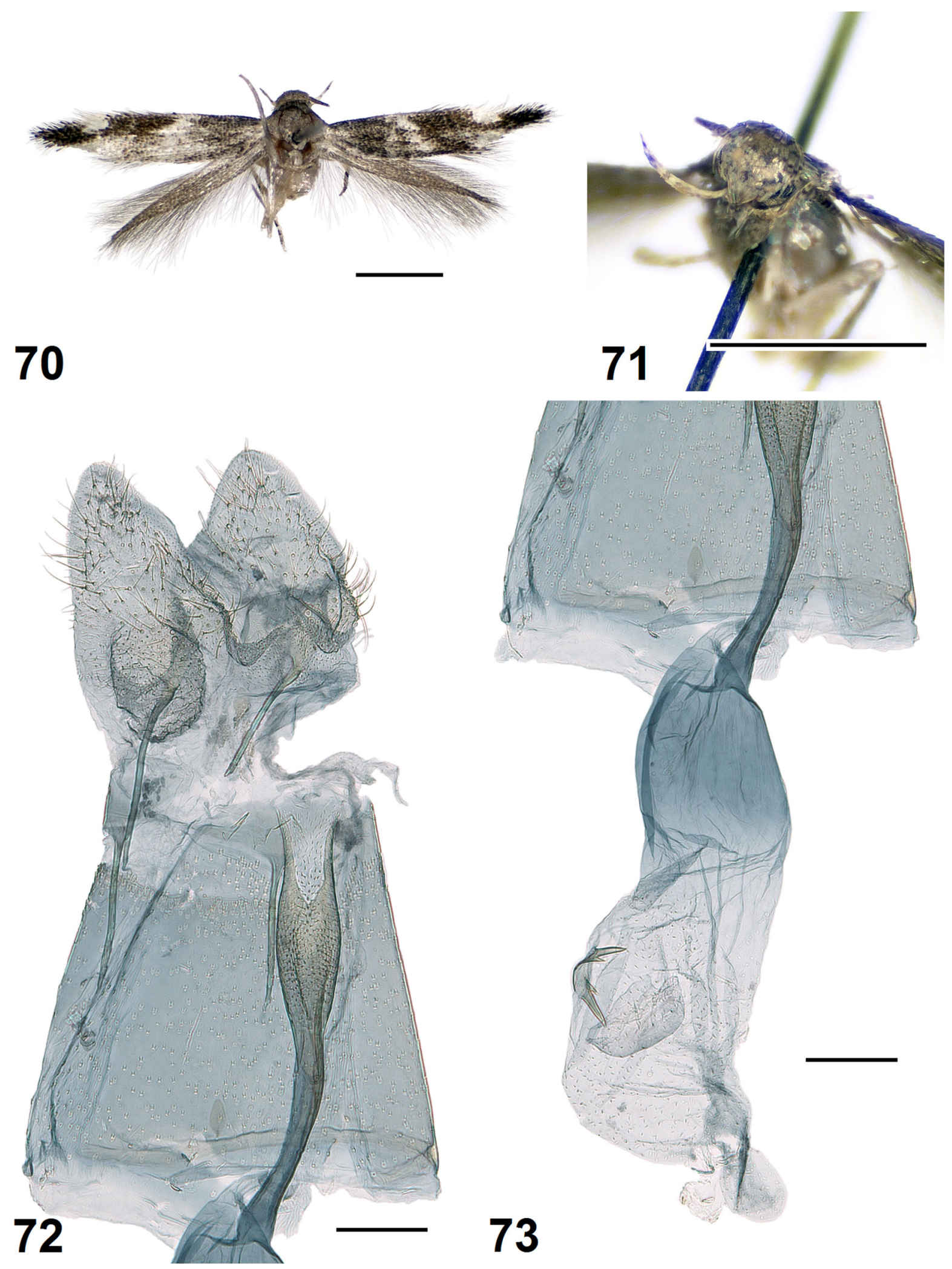

Figs 70-73. Elachista siamensis Sruoga \& Kaila sp. nov., paratype, + (ZMUC 2075). 70. Adult. 71. Head, latero-frontal view. 72. Female genitalia, caudal part. 73. Ductus and corpus bursae. Scale bars: $70-71=1 \mathrm{~mm} ; 72-73=0.1 \mathrm{~mm}$. 


\section{Female}

EXTERNAL CHARACTERs (Figs 70-71). Forewing length $2.8 \mathrm{~mm}$; wingspan $6.3 \mathrm{~mm}(\mathrm{n}=1)$. Otherwise as male, but forewing more brightly coloured with ground colour dark blackish brown; fascia, costal and tornal spots white.

Female genitalia (Figs 72-73). Papilla analis setose, triangular. Apophysis posterioris slightly longer than apophysis anterioris. Ostium bursae in posterior margin of sternum 7, dorsal wall spinose. Ventral margin of ostium bursae deeply incised, narrow and V-shaped. Antrum rather short, approximately as long as apophysis posterioris and nearly three times as broad as colliculum. Inner side of antrum with minute spines. Anterior margin of sternum 7 reinforced. Colliculum as long as antrum, bent, more sclerotized on one side. Corpus bursae oval, covered by minute internal spines except caudally; signum oval sclerotized plate with pair of large apposite teeth and two small accessory teeth.

\section{Biology}

Unknown.

\section{Flight period}

Based upon specimens available, adults fly in September and October.

\section{Distribution}

So far this species is known only from northeastern and central Thailand.

\section{Remarks}

The putative association of male and female is based on similar appearance and on the occurrence at the same locality. Moths were caught at the same site and time.

The gnathos is slightly wider in two paratypes (slide numbers L. Kaila 1500 and 1504). In the absence of other reliable differences, we consider this as minor variation of the same species.

\section{Discussion}

With the description of Urodeta longa Sruoga \& Kaila sp. nov., the genus Urodeta is recorded for the Asia only for the second time. The occurrences of the new species, along with Urodeta noreikai Sruoga \& De Prins, 2013 recently described from Nepal and two species, Urodeta inusta Kaila, 2011, Urodeta sp. from Australia, suggest a wider distribution of this enigmatic genus in the Oriental region than actually recorded. Unfortunately, there are still no documented data available on the biology of the Urodeta species in Asia.

All known species related to E. albrechti and E. heteroplaca and with known life histories feed on bamboos. In Asia, the diversity of bamboos is huge, with hundreds of species. If Elachista species specializing in them even marginally match this diversity, one may assume that a vast diversity of elachistines are is awaiting discovery.

In conclusion, our knowledge of the subfamily Elachistinae in Thailand is far from complete, leaving a large gap in our understanding of these moths. A great amount of work still needs to be done - from collecting to the description of new taxa and recording the natural history of species.

We are aware that describing new species on the basis of one or very few specimens can cause problems. However, the species presented here are characteristic each. Moreover, given how few specimens in total are known from Thailand or from the Oriental region in general so far, one can assume that it may take 
considerable time before further material is available. Eventual barcoding - unfortunately not possible for the authors at present - of these specimens will likely reduce the risk of future problems with taxonomy.

\section{Acknowledgements}

We extend our sincere thanks to Ole Karsholt for giving access to the material at ZMUC, and in particular Markku J. Pellinen who has donated his invaluable material to MZH. We also thank anonymous reviewers for helpful comments.

\section{References}

Bland K.P. 1996. Elachistidae. In: Emmet A.M. (ed.) The Moths and Butterflies of Great Britain and Ireland. Volume 3: 339-410. Harley Books, Colchester.

Braun A. 1948. Elachistidae of North America (Microlepidoptera). Memoirs of the American Entomological Society 13: 1-110.

Kaila L. 1995. A revision of the North American Perittia (=Onceroptila), with first Nearctic records of the genus Mendesia (Elachistidae). Journal of the Lepidopterist's Society 49 (3): 208-222.

Kaila L. 1996. Revision of the Nearctic species of Elachista I. The tetragonella group (Lepidoptera: Elachistidae). Entomologica scandinavica 27: 217-238. https://doi.org/10.1163/187631296X00061

Kaila L. 1997. A revision of the Nearctic species of Elachista s.1. II. The argentella group (Lepidoptera: Elachistidae). Acta Zoologica Fennica 206: 1-93.

Kaila L. 1998. Redescriptions of three Meyrick's Asiatic elachistid species, with descriptions of two new species (Lepidoptera, Gelechioidea). Entomologica Fennica 9: 53-63. https://doi.org/10.33338/ef.83966

Kaila L. 1999a. Phylogeny and classification of the Elachistidae s.s. (Lepidoptera: Gelechioidea). Systematic Entomology 24 (2): 139-169. https://doi.org/10.1046/j.1365-3113.1999.00069.x

Kaila L. 1999b. A revision of the Nearctic species of the genus Elachista s.l. III. The bifasciella, praelineata, saccharella and freyerella groups (Lepidoptera, Elachistidae). Acta Zoologica Fennica 211: 1-235.

Kaila L. 2011. Elachistine Moths of Australia (Lepidoptera: Gelechioidea: Elachistidae). Monographs on Australian Lepidoptera 11. CSIRO Publishing, Melbourne.

Kaila L. 2015a. The Elachista dispunctella (Duponchel) complex (Lepidoptera, Elachistidae) revisited, with exceptional level of synonymy. Zootaxa 3980 (3): 301-358.

https://doi.org/10.11646/zootaxa.3980.3.1

Kaila L. 2015b. New Palearctic species of the Elachista bifasciella group (Lepidoptera: Gelechioidea, Elachistidae). SHILAP Revista de lepidopterología 43 (171): 385-423.

Kaila L. 2017. First records of Elachistinae from New Caledonia: evidence of repeated dispersal events with Australia (Lepidoptera, Gelechioidea, Elachistidae). Zootaxa 4300 (4): 536-550.

https://doi.org/10.11646/zootaxa.4300.4.4

Kaila L. 2019. An annotated catalogue of Elachistinae of the World (Lepidoptera: Gelechioidea: Elachistidae). Zootaxa 4632 (1): 1-231. https://doi.org/10.11646/zootaxa.4632.1.1

Kaila L. \& Nupponen K. 2017. On species related to Elachista deceptricula Staudinger, 1880 with descriptions of three new species (Lepidoptera: Elachistidae). SHILAP Revista de lepidopterología 45 (179): 415-428.

Kaila L. \& Nupponen K. 2018. A review of the Elachista subula Parenti species complex (Lepidoptera, Elachistidae), with descriptions of nine new Palearctic species. Zootaxa 4433 (3): 401-433.

https://doi.org/10.11646/zootaxa.4433.3.1 
Kaila L. \& Sugisima K. 2011. 1. Phylogeny, subfamily definition and generic classification. In: Kaila L. Elachistine Moths of Australia (Lepidoptera: Gelechioidea: Elachistidae). Monographs on Australian Lepidoptera 11: 7-22. CSIRO Publishing, Melbourne.

Kaila L., Baran T. \& Mutanen M. 2015. A revision of the Elachista dispilella complex (Lepidoptera: Gelechioidea: Elachistidae). Zootaxa 3963 (4): 517-560. https://doi.org/10.11646/zootaxa.3963.4.3

Kristensen N.P. 2003. Skeleton and muscles: adults. In: Kristensen N.P. (ed.) Lepidoptera, Moths and Butterflies. Vol. 2. Morphology, Physiology, and Development: 39-122. Walter de Gruyter, Berlin/New York. https://doi.org/10.1515/9783110893724.39

Parenti U. 1983. Elachistidi del Giappone (Lepidoptera, Elachistidae). Bollettino del Museo Regionale di Scienze Naturali - Torino 1 (1): 1-20.

Parenti U. \& Varalda P.J. 1994. Gli Elachistidi (Lepidoptera, Elachistidae) e le loro piante ospiti. Bollettino del Museo Regionale di Scienze Naturali - Torino 12 (1): 73-136.

Robinson G.S. 1976. The preparation of slides of Lepidoptera genitalia with special reference to the Microlepidoptera. Entomologist's Gazette 27: 127-132.

Sinev S.Yu. \& Sruoga V.A. 1997. Fam. Elachistidae (Lepidoptera). In: Ler P.A. (ed.) Key to the Insects of Russian Far East. Vol. V. Trichoptera and Lepidoptera. Part 1: 491-502. Dal'nauka, Vladivostok. [In Russian]

Sruoga V. 1995. Description of Cosmiotes cornutifera sp. $n$. and a provisional check-list of Elachistidae fauna of Far-Eastern Russia (Lepidoptera, Elachistidae). Phegea 23 (3): 157-162.

Sruoga V. 2005. Redescriptions of two of Meyrick's types of Elachistidae (Lepidoptera: Gelechioidea) from India and Sri Lanka. Acta Zoologica Lituanica 15 (1): 58-61.

https://doi.org/10.1080/13921657.2005.10512610

Sruoga V. \& De Prins J. 2013. A new species of Urodeta (Lepidoptera: Elachistidae: Elachistinae) from Nepal, the first record of the genus from Asia, showing an ancient distribution pattern. Zootaxa 3599 (1): 94-100. https://doi.org/10.11646/zootaxa.3599.1.9

Sruoga V. \& Diškus A. 2006. Redescription of the type specimens of the Elachista freyerella speciesgroup (Lepidoptera: Elachistidae: Elachistinae) from India and Sri Lanka. Zootaxa 1350: 33-43. https://doi.org/10.11646/zootaxa.1350.1.3

Sruoga V., Sinev S.Yu. \& Rocienè A. 2017. The Elachistidae (Lepidoptera: Gelechioidea) of Caucasus, with description of three new species. Zootaxa 4338 (2): 241-262.

https://doi.org/10.11646/zootaxa.4338.2.2

Sugisima K. 2005a. A revision of the Elachista praelineata-group (Lepidoptera, Elachistidae) in Japan, with comments on morphology of the pupa in Elachista. Tijdschrift voor Entomologie 148: 1-19. https://doi.org/10.1163/22119434-900000160

Sugisima K. 2005b. Japanese Elachista studied by Parenti (1983) (Lepidoptera, Elachistidae): the subgenus Aphelosetia and the gleichenella-, tetragonella-, and bifasciella-groups. Tijdschrift voor Entomologie 148: 225-246. https://doi.org/10.1163/22119434-900000171

Sugisima K. 2006. A new species of the Elachista freyerella-group (Elachistidae s. str.) from Japan. Transactions of the Lepidopterological Society of Japan 57 (1): 70-80.

Sugisima K. \& Kaila L. 2005. Japanese Elachista (Lepidoptera, Elachistidae s. str.) mining on the leaf of woody Poaceae. Entomologica Fennica 16: 83-102.

Traugott-Olsen E. \& Nielsen E.S. 1977. The Elachistidae (Lepidoptera) of Fennoscandia and Denmark. Fauna Entomologica Scandinavica 6: 1-299. 
Manuscript received: 20 June 2019

Manuscript accepted: 22 August 2019

Published on: 5 November 2019

Topic editor: Gavin Broad

Desk editor: Pepe Fernández

Printed versions of all papers are also deposited in the libraries of the institutes that are members of the EJT consortium: Muséum national d'histoire naturelle, Paris, France; Meise Botanic Garden, Belgium; Royal Museum for Central Africa, Tervuren, Belgium; Royal Belgian Institute of Natural Sciences, Brussels, Belgium; Natural History Museum of Denmark, Copenhagen, Denmark; Naturalis Biodiversity Center, Leiden, the Netherlands; Museo Nacional de Ciencias Naturales-CSIC, Madrid, Spain; Real Jardín Botánico de Madrid CSIC, Spain; Zoological Research Museum Alexander Koenig, Bonn, Germany; National Museum, Prague, Czech Republic. 